\title{
Compósito cimentício com elevado teor de fibra de coco tratada: propriedades físicas e durabilidade
}

\author{
Cement composite with high content treated \\ coconut fiber: physical properties \\ and durability
}

Everton Jose da Silva ${ }^{1}$, Fermin Garcia Velasco ${ }^{2}$, Francisco Martinez Luzardo ${ }^{2}$ Maria Lidiane Marques ${ }^{1}$, Felix Mas Milian ${ }^{2}$, Luciano Brito Rodrigues ${ }^{3}$

\author{
${ }^{1}$ Doutor (a) - IFBA - Instituto Federal de Educação, Ciência e Tecnologia da Bahia, CP: 45.823-431, Eunápolis, BA, \\ Brasil. e-mail: js_everton@yahoo.com.br; lidiane_marques@yahoo.com.br \\ ${ }^{2}$ Doutor - UESC - Universidade Estadual de Santa Cruz, CP: 45.662-900, Ilhéus, BA, Brasil. \\ e-mail: fermingv@gmail.com, fmartinezluzardo@gmail.com, f.mas.milian@gmail.com \\ ${ }^{3}$ Doutor - UESB - Universidade Estadual do Sudoeste da Bahia, CP: 45.700-000, Itapetinga, BA, Brasil. \\ e-mail: rodrigueslb@gmail.com
}

\begin{abstract}
RESUMO
O aproveitamento da fibra de coco na construção civil pode diminuir o consumo de agregados minerais como areia e brita, e melhorar propriedades físicas e mecânicas de um compósito cimentício. No entanto, um dos pontos mais precários está relacionado à degradação acelerada da fibra vegetal pela ação química da matriz cimentícia. Então, avaliou-se a incorporação da fibra de coco com um novo tratamento, e sua influência nas propriedades físicas e durabilidade do compósito cimentício. O tratamento utilizou látex natural, sílica ativa e fibra de coco na proporção de $10 \%$, em relação à massa de cimento, para a produção de corpos de prova. Foram determinadas as capacidades de atenuação térmica e acústica, massa específica e executados ensaios mecânicos e de durabilidade. Os dados experimentais indicaram melhora do desempenho termoacústico do novo compósito em até $20 \%$ por comparação com o desempenho do compósito cimentício sem a sua presença. Os resultados preliminares obtidos permitem concluir que o compósito pode ser aproveitado na construção civil para produção de tijolos de alvenaria para vedação.
\end{abstract}

Palavras-chave: Materiais alternativos de construção, Fibras vegetais, Durabilidade, Sustentabilidade.

\begin{abstract}
The use of coconut fiber in construction can both reduce the consumption of mineral aggregates as sand and gravel and it is improves physical and mechanical properties of cementitious composite. However, one of the weakest points in application of new cementitious composites with coconut fibers is related to the accelerated degradation of plant fiber by chemical action of cementitious matrix. So, this paper evaluated the incorporation of coconut fiber with a new treatment, and its influence on physical properties and durability of cementitious composite. The treatment used natural latex, silica fume and coconut fiber, $10 \%$ in relation to the mass cement, was used in the production of specimens. They were determined thermal and acoustic attenuation capability, specific gravity and performing mechanical testing and durability. The experimental data indicated an improvement in the thermoacoustic performance of the new composite by up to $20 \%$ compared to the performance of the cementitious composite without its presence. The preliminary results obtained allow us to conclude that the composite can be used in the construction industry for the production of masonry bricks for sealing.
\end{abstract}

Keywords: Alternative construction materials, Vegetable fibers, Durability, Sustainability.

\section{INTRODUÇÃO}

A utilização de fibras vegetais em novos materiais de construção pode contribuir para diminuir a extração de recursos não renováveis necessários para a produção de alguns compósitos cimentícios. De acordo com De- 
partamento Nacional de Produção Mineral - DNPM [1], a produção de brita e cascalho no Brasil, em 2014, registrou 308 milhões de toneladas, valor 5,2\% maior que em 2013. Em relação à areia, o aumento no período foi de 3,9\%, atingindo 391 milhões de toneladas. Dessa forma, em 2014 foram extraídas da natureza aproximadamente 700 milhões de toneladas de materiais para serem utilizados como agregados na construção civil. Em relação à comercialização de cimento Portland, aproximadamente 70 milhões de toneladas foram fabricadas em 2013 (SNIC - Sindicato Nacional da Indústria do Cimento [2]). Além da extração de argila e calcário para a produção de cimento Portland, a fabricação de uma tonelada de clínquer, sua matériaprima, lança aproximadamente uma tonelada de $\mathrm{CO}_{2}$ na atmosfera (METHA e MONTEIRO [3]).

\section{A PERTINÊNCIA DO USO DE FIBRAS DE COCO EM NOVOS MATERIAIS DE CONSTRUÇÃO}

Em relação ao coco (Cocos Nucifera), de acordo com o IBGE (Instituto Brasileiro de Geografia e Estatística), através do LSPA (Levantamento Sistemático da Produção Agrícola 2016), a produção de coco no Brasil alcançou 1.896.124 toneladas na safra 2015(IBGE [4]). Considerando que aproximadamente 10\% da massa do fruto é constituída por fibras, o volume gerado em 2015 foi de aproximadamente $960 \mathrm{mil} \mathrm{m³}$ de fibra de coco. Esta grande e crescente quantidade, se não devidamente aproveitada, gera grande demanda de área para deposição do resíduo, contribui para a proliferação de vetores em razão do acúmulo de água nas cascas, além de emitir gás metano. Quando não é devidamente aproveitado e descartado inadequadamente, este material pode trazer consequências nocivas ao meio ambiente e à saúde pública.

Ante estas duas questões ambientais, acima descritas, aparece a possibilidade de desenvolver novas tecnologias que contribuam para resolver ambas questões simultaneamente: diminuição da extração de recursos naturais para a construção civil com a utilização de resíduos agroflorestais descartados in natura no meio ambiente. O emprego de fibras de coco em compósitos cimentícios pode contribuir para dar uma destinação adequada a este resíduo, pois a presença das fibras vegetais diminui a densidade e aumenta o desempenho termoacústico dos compósitos. Do ponto de vista mecânico, a utilização de fibras em matrizes aumenta a ductilidade e as resistências à tração, à flexão, ao impacto, além de alterar o seu comportamento pósfissuração (AGOPYAN e SAVASTANO JUNIOR [5]). Entretanto, a utilização efetiva de fibras vegetais em compósitos cimentícios exige o desenvolvimento de uma tecnologia adequada que permita evitar ou atenuar o processo de degradação que as fibras sofrem no interior das matrizes cimentícias.

\section{TRATAMENTOS PARA ADEQUAR AS FIBRAS DE COCO EM COMPÓSITOS CIMENTÍCIOS}

A durabilidade dos compostos de cimento Portland, como, p.ex., uma argamassa ou concreto, está vinculada ao tempo no qual o mesmo mantém suas resistências (mecânicas e químicas) e não apresenta sinais de fissuração ou deterioração (desgaste visual na sua superfície ou no volume, que pode reduzir seu peso ou massa específica). Os principais agentes agressivos são: temperatura, ação do fogo e de fluidos agressivos de toda espécie.

Uma vez inserida em materiais cimentícios, as fibras vegetais ficam submetidas ao contato com alguns subprodutos gerados no processo de hidratação do cimento, dentre os quais o hidróxido de cálcio tem significativa expressão, devido a elevar o $\mathrm{pH}$ da matriz cimentícia. $\mathrm{Na}$ formação de compósitos cimentícios com fibras vegetais, o meio alcalino constitui uma agressão à estrutura fibrosa vegetal. Nesta situação, as fibras vegetais sofrem degradação acelerada, com destruição parcial da estrutura celulósica e, consequentemente, diminuindo drasticamente suas propriedades físicas e químicas (PEREIRA et al. [6]).

Este fenômeno da perda de lignina da fibra dentro do compósito, pode estar associado aos resultados obtidos por TOLÊDO FILHO et al. [7]. Esses autores avaliaram a durabilidade de fibras de coco expostas a soluções alcalinas de hidróxido de cálcio pH 12 e constataram que as fibras perderam completamente sua resistência depois de 300 dias. Segundo os autores, a fragilização das fibras pode ser associada principalmente a outra causa: a sua mineralização devido à migração de produtos de hidratação para o interior da fibra, especialmente o hidróxido de cálcio.

No sentido de melhorar a durabilidade dos compósitos com fibras vegetais, há algumas possibilidades de tratamento das fibras em desenvolvimento apontadas por ARSĖNE et al. [8] como: mercerização, tratamentos com ácidos, pirólise e revestimento com silano. Por outro lado, SANTOS et al. [9] sugerem: modificação da superfície das fibras; uso de pozolanas; aceleração por carbonatação; aplicações da nanociência e utilização do processo de extrusão. PEREIRA [10] testou três tipos de tratamentos a saber: ultrassom (tratamento físico através de ondas sonoras em água), ultrassom combinado com silicato de sódio e sulfato de alumínio, e ultrassom combinado com álcool furfurílico. Ao final do trabalho, concluiu-se que os tratamentos propostos para melhorar a viabilidade do uso da fibra da casca do coco verde não se mostraram muito eficientes, demonstrando que esta questão continua em aberto no meio científico. 
Dentre os tratamentos citados, o uso de materiais pozolânicos tem se mostrado promissor, porém, essa solução exige a utilização de aditivos plastificantes para melhorar a plasticidade no estado fresco do compósito, o que eleva seu custo de produção.

Uma possibilidade, ainda pouco estudada, que poderia eliminar o uso dos ativos redutores de água em compósitos cimentícios com adição de fibras é o emprego de látex em conjunto com pozolanas. A principal vantagem do uso de látex em compósitos cimentícios com fibras vegetais está associado a menor quantidade de $\mathrm{CH}$ (hidróxido de cálcio) gerada no processo de hidratação. Ocorre uma diminuição do transporte de íons na água contida nos poros através da redução do espaço disponível pelo filme polimérico (AFRID et al. [11] e BIJEN [12]). Esta característica aliada ao poder adesivo do látex para adsorver a pozolana, poderia promover reações pozolânicas locais no interior da matriz cimentícias que protegeriam a superfície da fibra de coco do ataque alcalino.

Nesse sentido, o objetivo do presente trabalho é produzir um compósito cimentício com elevado teor de fibra de coco utilizando o tratamento protetor desenvolvido por SILVA et al. [13] e avaliar suas propriedades físicas e durabilidade.

\section{MATERIAIS E MÉTODOS}

\subsection{Materiais}

O cimento Portland utilizado foi CP V ARI - Cimento Portland de Alta Resistência Inicial em virtude da sua maior velocidade de hidratação e de possuir menor teor de adições minerais que poderiam influenciar os tratamentos da fibra de coco. A água potável usada para confecção dos corpos de prova foi deionizada em um dispositivo de troca iônica (marca Marte, modelo DM-50). O látex natural de borracha em estado líquido, com concentração de $53 \%$ (p/p), foi fornecido pela empresa Mucambo (Ilhéus, Bahia). Adotou-se a metodologia desenvolvida por SILVA et al. [13] com o uso das pozolanas comerciais sílica ativa e metacaulim em proporções relativamente baixas para não prejudicar o processo de moldagem do compósito. Para atender ao elevado teor de fibras de coco utilizado nos corpos de prova, a empresa fornecedora das fibras a Coquefibras, localizada em Una, Estado da Bahia, forneceu as fibras de coco previamente cortadas com o comprimento de aproximadamente $25 \mathrm{~mm}$.

A Tabela 1 apresenta as quantidades de materiais utilizados nas misturas dos compósitos sem a presença de fibras (S-F), com elevada quantidade de fibra de coco natural (10\% em relação à massa de cimento - máxima quantidade de fibra possível de moldar sem prejudicar a consistência) "F-N" e das misturas com os tratamentos protetores para fibra de coco "S-L" para sílica ativa/látex e "M-L" para metacaulim/látex. As quantidades especificadas de cada material ou reagente químico, para sua respectiva mistura, foram estabelecidas para a produção de um mesmo volume de compósito, ou seja, 1 corpo de prova de 15×25×100 mm, a qual representa mais adequadamente as possíveis diferenças de comportamento dentre as formulações ensaiadas.

Tabela 1: Dosagem dos materiais e reagentes químicos empregados na confecção dos corpos de prova.

\begin{tabular}{c|c|c|c|c|c|c}
\hline $\begin{array}{c}\text { NOMENCLA- } \\
\text { TURA DO } \\
\text { COMPÓSITO }\end{array}$ & $\begin{array}{c}\text { ÁGUA } \\
(\mathbf{g})\end{array}$ & $\begin{array}{c}\text { LÁTEX NATURAL-53\% } \\
\mathbf{p} / \mathbf{p}(\mathbf{g})\end{array}$ & $\begin{array}{c}\text { SÍLICA } \\
\text { ATIVA (g) }\end{array}$ & $\begin{array}{c}\text { METACAULIM } \\
(\mathbf{g})\end{array}$ & $\begin{array}{c}\text { FIBRA DE } \\
\text { COCO NA- } \\
\text { TURAL (g) }\end{array}$ & $\begin{array}{c}\text { CIMENTO } \\
\text { PORTLAND } \\
\text { CP-V (g) }\end{array}$ \\
\hline S-F & 28 & - & - & - & - & 40 \\
\hline F-N & 24,5 & - & - & - & 3,5 & 35 \\
\hline S-L & 24,04 & 0,46 & 3,5 & - & 3,5 & 31,5 \\
\hline M-L & 24,04 & 0,46 & - & 3,5 & 3,5 & 31,5 \\
\hline
\end{tabular}

Uma sequência de produção, individual para cada corpo de prova, foi adotada para otimizar o processo e garantir a trabalhabilidade e a consistência adequada, visto que não foram utilizados aditivos plastificantes redutores de água. A mistura S-F foi preparada através da homogeneização simples (manual com espátula) entre o cimento e água durante 30 s. Já na mistura F-N, houve um contato inicial entre a fibra e a água, durante 30 s e, então, foi adicionado o cimento para a segunda homogeneização durante 30s.

Para as misturas com as fibras de coco tratadas (S-L e M-L), pesou-se água mais látex mais fibra para a primeira homogeneização durante 30s (Figura 1A), posteriormente adicionou-se a pozolana (sílica ativa ou metacaulim) para a segunda homogeneização. Nesta etapa as fibras de coco lubrificadas com látex natural adsorvem a pozolana em volta da sua superfície em função do poder adesivo do látex natural. 
a)

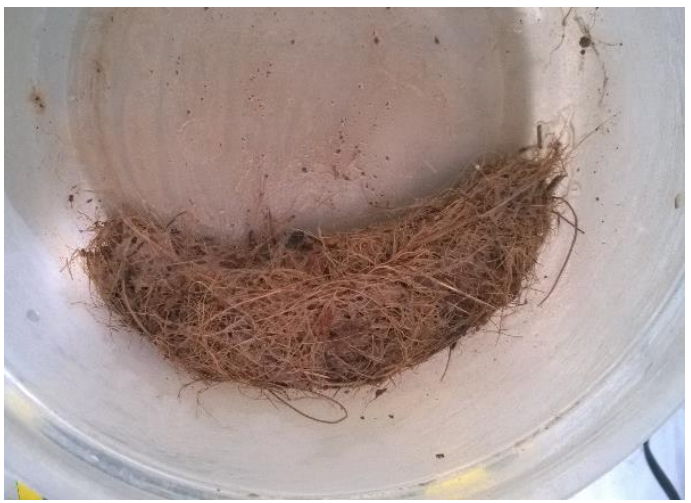

c)

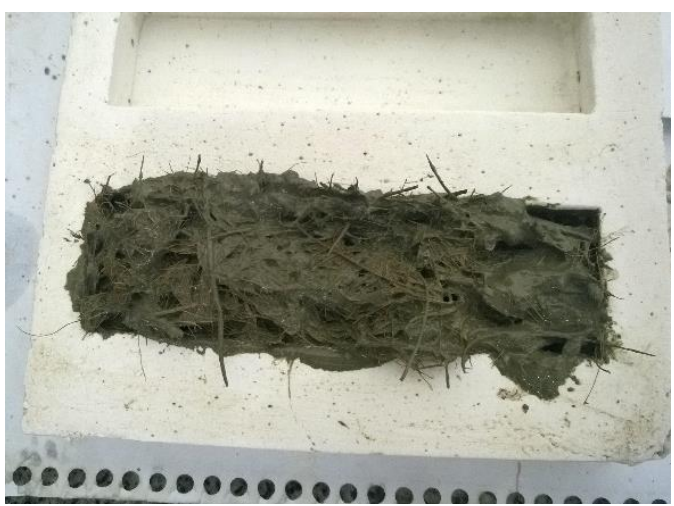

b)

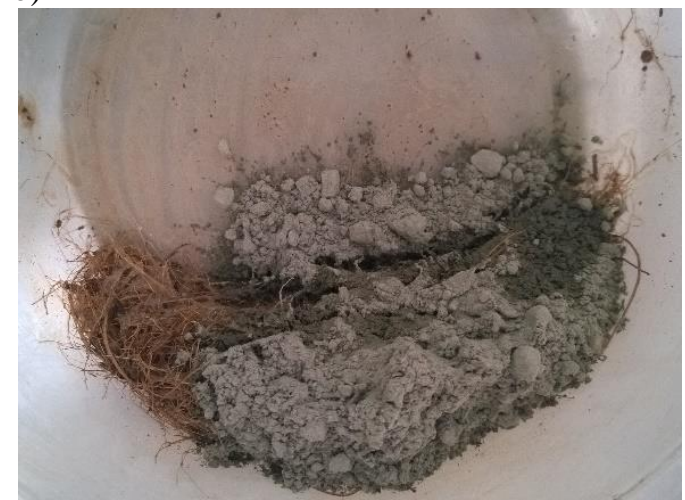

d)

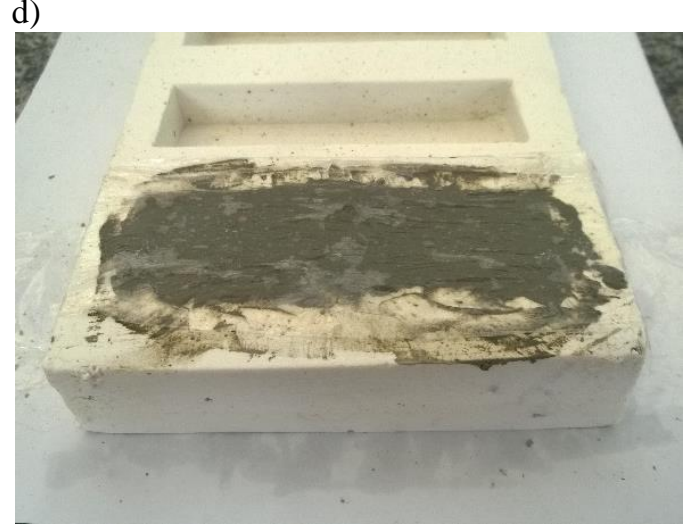

Figura 1: Processo de mistura entre água, fibra de coco e látex (A); momento da colocação do cimento na mistura (B); moldagem do compósito produzido (C); Finalização do processo de produção com colocação do filme plástico sobre o corpo de prova (D).

Depois disso, adicionou-se a massa do cimento Portland (Figura 1B) para finalizar a sequência de mistura e moldagem manual dos corpos de prova no molde de silicone através de adensamento e compactação (Figura 1C). Ressalta-se que as quantidades de cada mistura descrita na Tabela 1 foram totalmente consumidas para a produção individual de cada corpo de prova correspondente a sua respectiva mistura. Após a moldagem e "acabamento" com a ponta da colher de pedreiro, o corpo de prova foi coberto por um filme plástico (Figura 1D), durante $24 \mathrm{~h}$, para posterior processo de cura imersa em água durante 28 dias.

\subsection{Propriedades Físicas}

\subsubsection{Determinação da massa específica dos corpos de prova}

Com os corpos de prova no estado endurecido, a primeira propriedade física específica determinada foi a massa específica dos compósitos de cada mistura. Após 28 dias de cura imersa em água, eles foram secos em estufa por $24 \mathrm{~h}$ a temperatura de $105+/-5^{\circ} \mathrm{C}$ até atingir pesagem constante. Posteriormente, após o resfriamento dos corpos de prova até atingirem a temperatura ambiente, eles foram devidamente medidos com paquímetro digital e pesados novamente (balança analítica de alta precisão até $10^{-4} \mathrm{~g}$ ) para determinação da sua massa. Através da relação entre a massa obtida e o volume calculado obteve-se massa específica de cada corpo de prova. Foram utilizados 5 corpos de prova de cada mistura para realização da análise de variância de classificação simples e análise múltipla de médias de Duncan a um nível de confiabilidade de 0,95.

\subsubsection{Determinação dos índices de avaliação do desempenho termoacústico}

Para análise do desempenho térmico e acústico dos compósitos produzidos foi utilizada a norma ABNT NBR 15575 [14] como base na montagem de uma caixa termoacústica. A referida norma estabelece níveis de temperaturas aceitáveis no interior das edificações no verão e no inverno. Em relação ao desempenho acústico, a norma considera o "índice de redução sonora" para avaliar a capacidade de isolamento acústico dos materiais. É importante ressaltar que os experimentos desenvolvidos tiveram por objetivo executar uma análise prévia do desempenho termoacústico do compósito com fibra de coco e não foram realizados em laboratórios técnicos especializados nesta finalidade. 
Para a execução desses ensaios foi utilizada uma caixa térmica de isopor com capacidade de 1,5 L, marca "Fricalor" e espessura das paredes com $15 \mathrm{~mm}$. No centro de cada uma das quatro faces laterais da caixa foram instalados os corpos de prova S-F e S-L, sempre com 28 dias de idade. É importante ressaltar que para o teste termoacústico foram utilizados corpos de prova de diferentes espessuras ( 15 e $50 \mathrm{~mm}$ ) com o intuito de avaliar a influência da espessura dos mesmos em relação à capacidade de isolação térmica e acústica. Foram utilizados quatro corpos de prova no total, dois com fibra de coco tratada com látex natural e sílica ativa (S-L15 e S-L50) e dois sem fibra (S-F15 e S-F50), conforme Figura 2A. Nas faces laterais com corpos de prova de $50 \mathrm{~mm}$ de espessura, foi necessário adicionar novas camadas de isopor com o objetivo de garantir a adequada isolação térmica do sistema. Uma camada de espuma de poliuretano com $20 \mathrm{~mm}$ de espessura foi utilizada como revestimento externo da caixa para garantir o isolamento termoacústico do sistema de medição (Figura 2B). O projeto de montagem do sistema é apresentado na Figura 2C (planta baixa) e na Figura 2D (perspectiva).

a)

b)

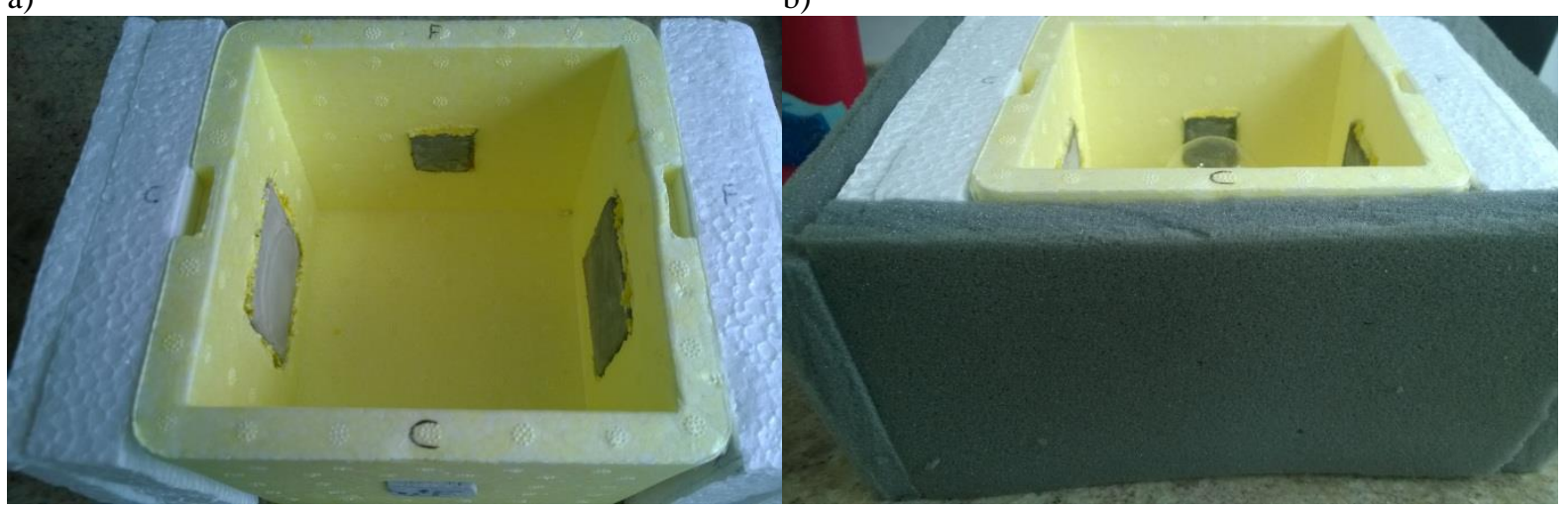

c)

d)
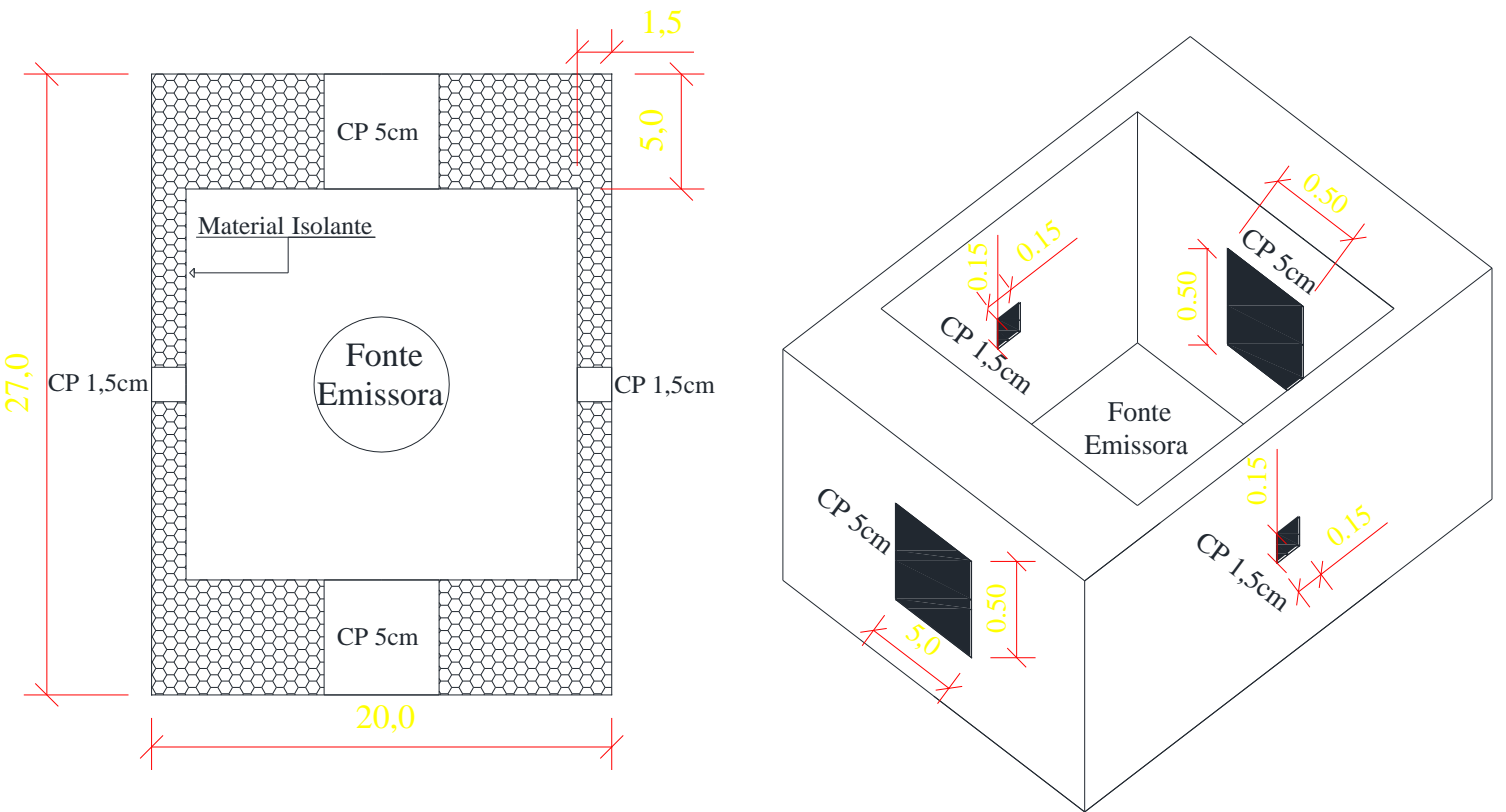

Figura 2: Caixa de isopor com os corpos de prova de 15 e $50 \mathrm{~mm}$ instalados nas paredes laterais e camada extra de isopor para os corpos de prova de $50 \mathrm{~mm}$ (A); Caixa com o revestimento externo de espuma de poliuretano (B); Montagem do sistema - planta baixa (C); Montagem do sistema - perspectiva (D).

No interior da caixa duas fontes foram instaladas de maneira independente: uma fonte de calor - lâmpada incandescente (marca Tachiba, potência de 40W, 127V, fluxo lumisoso $410 \mathrm{~lm}$ e eficiência luminosa de $10,2 \mathrm{~lm} / \mathrm{W})$, conforme Figura 3A. Também, instalou-se uma fonte sonora: uma pequena caixa de som portátil modelo Speaker marca Sls-08 com potência de saída de $3 \mathrm{~W}$ (Figura 3B). A primeira foi utilizada para análise térmica e a segunda para análise acústica. 


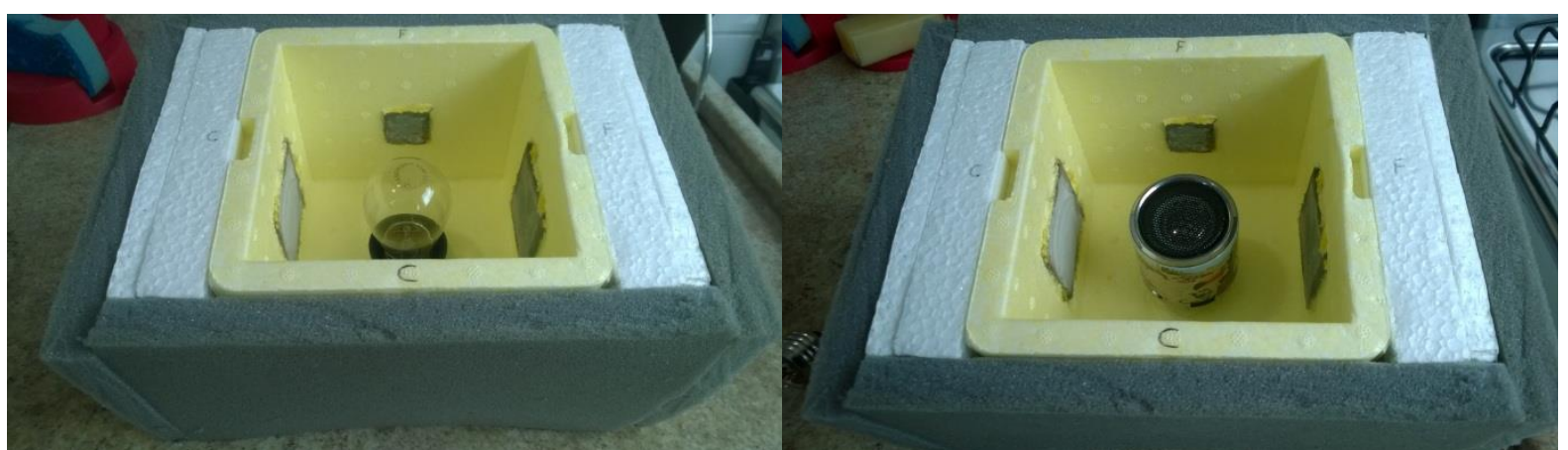

Figura 3: Caixa com a fonte de calor instalada - lâmpada incandescente (A); caixa com a fonte sonora instalada - caixa de som portátil (B).

Para medir as temperaturas foram utilizados seis termopares tipo K conectados a um receptor de sinais analógico acoplado a uma placa de conversão analógica-digital ("placa Arduino") instalada em um computador AMD FX ${ }^{\mathrm{TM}}$ - 4100 Quad Core, onde os dados gerados foram armazenados e processados. As leituras de temperatura em cada termopar foram programadas para serem realizadas em intervalo de tempo pré-fixado de 1 segundo. O sistema de aquisição de dados térmicos e acústicos que incluiu sua interface computacional foi desenvolvido no nosso laboratório (Centro de Tecnologia das Radiações) e é denominado SYSTAC.

A lâmpada foi ligada até a temperatura no interior da caixa atingir $55+/-5^{\circ} \mathrm{C}$ em um primeiro ciclo e posteriormente $65+/-5^{\circ} \mathrm{C}$ no segundo ciclo. Esta metodologia foi determinada com o objetivo de determinar a capacidade de isolação térmica dos corpos de prova através da detecção da temperatura registrada pelos sensores posicionados imediatamente à sua face externa. Foram realizadas três repetições de aquisição dos dados para calcular a curva média temperatura x tempo. Além disso, foram determinadas medidas de referência da temperatura no interior e exterior da caixa térmica, denominadas referência interna (REFI) e referência externa (REFE), respectivamente.

Com objetivo de se avaliar a capacidade de atenuação térmica relativa da incorporação das fibras nos corpos de prova, o indicador coeficiente de atenuação térmico relativo (CAT) foi calculado tanto para a espessura de $15 \mathrm{~mm}$, quanto para a espessura de $50 \mathrm{~mm}$ em função do tempo, conforme equações 1 e 2.

$$
\begin{aligned}
\operatorname{CAT}_{15} & =\frac{\mathrm{T}_{\text {ext. }}^{\text {SF15 }}}{\mathrm{T}_{\text {ext. }}^{\text {SL15 }}} \\
\text { CAT }_{50} & =\frac{\mathrm{T}_{\text {ext. }}^{\text {SF50 }}}{\mathrm{T}_{\text {ext. }}^{\text {SL50 }}}
\end{aligned}
$$

Onde:

$\mathrm{T}_{\text {ext }}$ : Temperatura externa ao corpo de prova

SF-15: Corpo de prova sem fibras e espessura de $15 \mathrm{~mm}$

SL-15: Corpo de prova com fibras e espessura de $15 \mathrm{~mm}$

SF-50: Corpo de prova sem fibras e espessura de $50 \mathrm{~mm}$

SL-50: Corpo de prova com fibras e espessura de $50 \mathrm{~mm}$

Já o indicador índice relativo de redução de temperatura $\gamma(\%)$ foi calculado em função da espessura do corpo de prova, conforme equação 3 .

$$
\gamma_{(\mathrm{e})}=\frac{\left(\mathrm{T}_{\mathrm{ext}}^{\mathrm{SF}}-\mathrm{T}_{\mathrm{ext} .}^{\mathrm{SL}}\right)}{\left(\mathrm{T}_{\mathrm{ext} .}^{\mathrm{SF}}-\mathrm{T}_{\mathrm{amb}}\right)}
$$

Onde:

$$
\begin{aligned}
& \mathrm{T}_{\text {ext }}: \text { Temperatura externa ao corpo de prova } \\
& \mathrm{SF}: \text { Corpo de prova sem fibras } \\
& \mathrm{SL}: \text { Corpo de prova com fibras } \\
& \text { e: espessura do corpo de prova } \\
& \mathrm{T}_{\mathrm{amb}}: \text { Temperatura ambiente }
\end{aligned}
$$

Nas mesmas condições experimentais, o gradiente de redução de temperatura por unidade de espessura $\beta$ (sem fibra S-F e com fibra S-L) - equações 4 e 5. 


$$
\begin{aligned}
& \beta_{(\mathrm{SF})}=\frac{\left(\mathrm{T}_{\text {int. }}-\mathrm{T}_{\text {ext. }}^{\mathrm{SF}}\right)}{\mathrm{e}} \\
& \beta_{(\mathrm{SL})}=\frac{\left(\mathrm{T}_{\text {int. }}-\mathrm{T}_{\text {ext. }}^{\mathrm{SL}}\right)}{\mathrm{e}}
\end{aligned}
$$

Onde:

$$
\begin{aligned}
& \mathrm{T}_{\text {int }}: \text { Temperatura interna da caixa } \\
& \mathrm{T}_{\text {ext }}: \text { Temperatura externa ao corpo de prova } \\
& \mathrm{SF}: \text { Corpo de prova sem fibras } \\
& \mathrm{SL}: \text { Corpo de prova com fibras } \\
& \text { e: espessura do corpo de prova }
\end{aligned}
$$

A eficiência de um tratamento acústico com materiais porosos e fibrosos é geralmente avaliada pelos seus coeficientes de absorção, que representam as medidas da fração de energia acústica absorvida pelo sistema em relação à energia acústica incidente. Para a aquisição dos dados, foi utilizado um decibelímetro digital marca Instrutherm modelo DEC-460 (operando no circuito de compensação A e resposta lenta - Slow) conectado a um receptor de sinais analógico acoplado a uma placa de conversão analógica-digital (placa) instalada em um computador DELL 14R i7, onde os dados gerados foram armazenados e processados. As leituras de intensidade sonora $(\mathrm{dB})$ em cada cabo conectado foram programadas para serem realizadas em intervalo de tempo pré-fixado de 1 segundo (software SYSTAC). A fonte sonora, no interior da caixa, foi acionada com a frequência variando de $20 \mathrm{kHz}$ até $20 \mathrm{~Hz}$ para a detecção da intensidade sonora com o decibelímetro devidamente posicionamento na face externa da caixa, imediatamente na face externa dos corpos de prova S-F15, S-F50, S-L15 e S-L50. O procedimento foi repetido três vezes para cada corpo de prova no intuito de verificar a diminuição da pressão sonora produzida pela incorporação das fibras de coco em relação à matriz cimentícia sem fibras. Para determinar a capacidade de atenuação acústica da incorporação das fibras nos corpos de prova, o indicador coeficiente de atenuação acústico relativo (CAC) foi calculado tanto para a espessura de 15, quanto para a espessura de $50 \mathrm{~mm}$ em função da frequência, conforme as equações 6 e 7 .

$$
\begin{aligned}
\mathrm{CAC}_{15} & =\frac{\mathrm{NIS}_{\text {ext. }}^{\text {SF15 }}}{\mathrm{NIS}_{\text {ext. }}^{\text {SL15 }}} \\
\mathrm{CAC}_{50} & =\frac{\mathrm{NIS}_{\text {ext. }}^{\text {SF50 }}}{\text { NIS }} \text { ext. }_{\text {SL50 }}^{\text {SL50 }}
\end{aligned}
$$

Onde:

NIS-ext.: Nível de Intensidade Sonora externa ao corpo de prova

SF-15: Corpo de prova sem fibras e espessura de $15 \mathrm{~mm}$

SL-15: Corpo de prova com fibras e espessura de $15 \mathrm{~mm}$

SF-50: Corpo de prova sem fibras e espessura de $50 \mathrm{~mm}$

SL-50: Corpo de prova com fibras e espessura de $50 \mathrm{~mm}$

Não foram executados ensaios complementares de análises térmicas para avaliar o comportamento dos corpos de prova acima das temperaturas de $60^{\circ} \mathrm{C}$, o que demandaria mais equipamentos analíticos e uma abordagem teórico-experimental complementar.

\subsection{Propriedades mecânicas e durabilidade}

\subsubsection{Procedimentos de cura}

Após o processo de moldagem dos corpos de prova (Figura 1), os mesmos foram submetidos a dois tipos de procedimentos de cura: o primeiro foi de 28 dias imersos em água; e o segundo, 28 dias imersos em água mais 14 ciclos de secagem e molhagem (ciclagem) com duração de $48 \mathrm{~h}$ cada. Ou seja, uma condição de envelhecimento acelerado para se avaliar o comportamento das fibras de coco tratadas no interior dos corpos de prova, conforme o trabalho de WEI e MEYER [15]. Estes autores também definem o ensaio mecânico de resistência à tração na flexão com três pontos para acompanhar o desempenho dos compósitos cimentícios após a condição de envelhecimento acelerado e fizeram um amplo estudo a respeito do processo de degradação da fibra de sisal (Agave Sisalana) inserida em compósito cimentício. Concluem que o envelhecimento 
acelerado, através de ciclos de secagem e molhagem com temperaturas elevadas, promove um efeito significativo de degradação e mineralização da fibra vegetal.

A partir dessas conclusões, o envelhecimento acelerado dos compósitos utilizados no presente trabalho consistiu em expor os cp's a ciclos de secagem e molhagem. Cada um dos 14 ciclos teve duração total de $48 \mathrm{~h}$ e consistiu de $24 \mathrm{~h}$ de secagem em estufa a $80 \pm 5^{\circ} \mathrm{C}$, e $24 \mathrm{~h}$ de imersão em água, também à temperatura de $80 \pm 5^{\circ} \mathrm{C}$.

\subsubsection{Ensaio de resistência mecânica à tração na flexão}

Posteriormente à realização dos dois procedimentos de cura, os corpos de prova foram submetidos ao ensaio mecânico de resistência à tração na flexão. Essas medidas foram determinadas em equipamento de ensaio universal marca TA.HD plus do fabricante Stable Micro Systems Ltd, UK, equipado com célula de carga de $750 \mathrm{~kg}$, devidamente calibrado e aplicando-se a velocidade de carga de $0,1 \mathrm{~mm} / \mathrm{min}$. Foram ensaiados 5 corpos de prova para cada tipo de mistura, produzidos de maneira independente. Os dados foram coletados e processados por meio do software Exponent (Stable Micro Systems Ltd, UK), que forneceu os resultados da força aplicada pelo em função do tempo. Para se conhecer o comportamento das diferenças entre as variáveis nos ensaios de durabilidade, utilizou-se a análise de variância de classificação simples e análise múltipla de médias de Duncan a um nível de confiabilidade de 0,95 . Foram confeccionados 5 corpos de prova para cada mistura, ou seja, 5 repetições para cada tipo de revestimento com produção individual de cada corpo de prova.

\subsubsection{Ensaio de resistência mecânica à compressão}

Para validar uma aplicação específica do compósito S-L, foram confeccionados tijolos maciços com as seguintes dimensões: $190 \mathrm{~mm}$ de comprimento, $90 \mathrm{~mm}$ de largura e $57 \mathrm{~mm}$ de altura, conforme a norma ABNT NBR 7170 [16]. O método de produção desses tijolos foi exatamente o mesmo adotado para a produção dos corpos de prova, descrito anteriormente. $\mathrm{O}$ ensaio de resistência à compressão foi realizado conforme a norma ABNT NBR 6460 [17] numa máquina de ensaio universal EMIC modelo PC200CS.

\section{RESULTADOS E DISCUSSÕES}

\subsection{Massas específicas dos corpos de prova}

Uma das propriedades mais influenciadas pela utilização das fibras de coco em compósitos cimentícios é a massa específica. Enquanto concretos convencionais possuem em média um valor de massa específica de 2,4 $\mathrm{g} / \mathrm{cm}^{3}$, GUNASEKARAN et al. [18] produziram concreto leve utilizando casca de coco substituindo o agregado graúdo e obtiveram $0,65 \mathrm{~g} / \mathrm{cm}^{3}$. A Figura 4 apresenta a redução dos valores de massa específica provocada pela substituição do cimento Portland pela fibra de coco. É importante destacar que a matriz cimentícia de referência sem fibras de coco (S-F) apresentou um valor relativamente baixo de massa específica devido à ausência de agregados na pasta de cimento e, principalmente, pelo uso de elevada relação água-cimento (ou fator a/c) utilizada $(0,7)$.

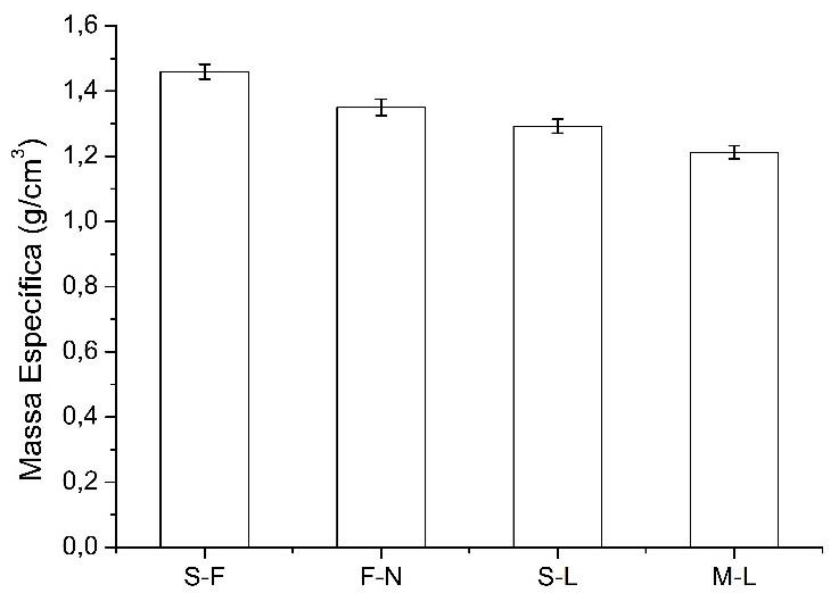

Figura 4: Resultado dos ensaios de determinação da massa específica dos corpos de prova S-F, F-N, S-L e M-L. 
A partir da substituição (em massa) de $10 \%$ de cimento Portland por fibra de coco, a massa específica dos corpos de prova diminuiu de aproximadamente $1,45(\mathrm{~S}-\mathrm{F})$ para $1,35 \mathrm{~g} / \mathrm{cm}^{3}(\mathrm{~F}-\mathrm{N})$. Esta diferença aumenta quando se compara as misturas com fibras tratadas com látex natural e pozolanas. Enquanto a mistura S-L apresentou 1,29, a mistura M-L apresentou o valor $1,21 \mathrm{~g} / \mathrm{cm}^{3}$. Isso pode ser atribuído às menores quantidade de cimento Portland utilizadas nas misturas S-L e M-L (ver Tabela 1), visto que a massa específica do aglomerante é maior que os correspondentes às pozolanas sílica ativa e metacaulim.

Além disso, considera-se que a presença de agentes tensoativos (partículas de polímero esféricas que variam entre 0,01 a $1 \mu \mathrm{m}$ ) do látex natural utilizado no tratamento pode gerar grandes quantidades de ar incorporado no compósito [3]. Esse fenômeno apresentou-se ligeiramente mais pronunciado na mistura tratada com a pozolana metacaulim, que obteve uma redução da massa específica de aproximadamente $17 \%$ em relação à mistura S-F, significativamente inferior de acordo com a análise múltipla de médias de Duncan. Esse resultado indica que o emprego de uma grande quantidade de fibra de coco associado ao tratamento com látex natural e pozolanas contribui diretamente para a redução da massa específica do compósito. Outros autores como GUNASEKARAN et al. [19] e ABDULLAH et al. [20] constataram que a incorporação da fibra de coco no concreto cumpre os requisitos necessários para a sua utilização como agregado leve.

\subsection{Indicadores de desempenho térmico}

A análise do desempenho térmico dos corpos de prova é apresentada na Figura 5 considerando-se os registros de temperaturas para o ambiente operacional e amostras estudadas. A curva denominada referência interior (REFI) corresponde à temperatura no interior da caixa térmica. Observa-se a elevação da temperatura a uma taxa de aproximadamente $4,8^{\circ} \mathrm{C} / \mathrm{min}$ para esta curva em virtude do acionamento da lâmpada incandescente e a conservação de calor dentro da caixa térmica.

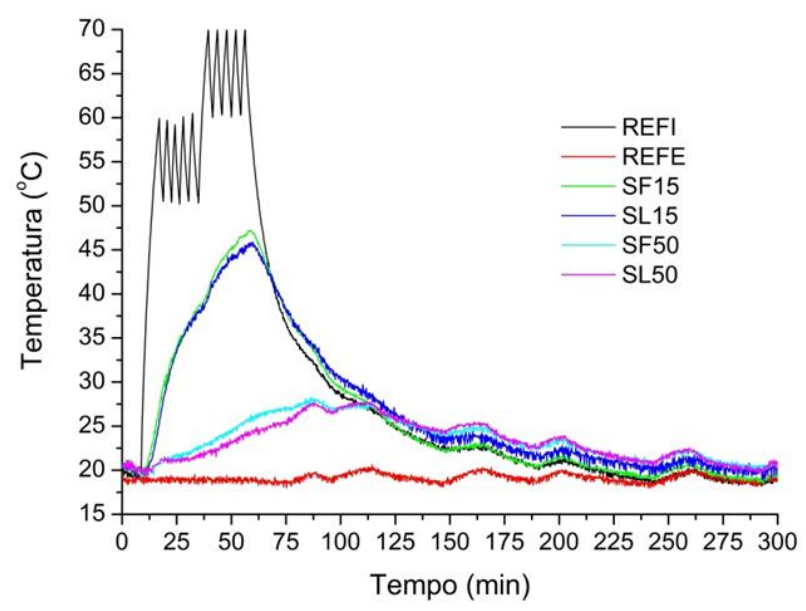

Figura 5: Gráfico dos resultados das temperaturas registradas nos ensaios de desempenho térmico dos corpos de prova SF15, S-L15, S-F50 e S-L50.

A curva REFI registrou o primeiro desligamento da lâmpada ao atingir a temperatura de $60^{\circ} \mathrm{C}$ e quando atingiu a temperatura de $50^{\circ} \mathrm{C}$ a lâmpada foi ligada novamente. Este processo se repetiu mais cinco vezes até a adequada distribuição de calor no interior do sistema. Posteriormente, o processo de ligaçãodesligamento foi repetido mais cinco vezes com o ciclo de temperatura variando entre 60 e $70^{\circ} \mathrm{C}$ até o seu último desligamento. Enquanto isso, a curva denominada referência externa (REFE) permaneceu no patamar de aproximadamente $19^{\circ} \mathrm{C}$, correspondente à temperatura ambiente do laboratório.

Em relação ao comportamento dos corpos de prova, observa-se que a ausência das fibras de coco nos corpos de prova S-F15 e S-F50 (sem fibra com 15 e $50 \mathrm{~mm}$ de espessura, respectivamente) facilitou a passagem de calor quando comparada aos corpos de prova com a presença de fibras de coco (S-L15 e S-L50). Esse comportamento pode estar associado à presença dos $10 \% \mathrm{p} / \mathrm{p}$ de fibra de coco que substituíram o cimento Portland. Segundo RODRÍGUEZ et al. [21], enquanto a condutividade térmica do concreto é $0,87 \mathrm{~W} / \mathrm{mK}$, a condutividade da fibra de coco é $0,048 \mathrm{~W} / \mathrm{mK}$. Por outro lado, a condutividade térmica da formulação cimento Portland-fibra proposta por RAMIREZ et al. [22] é $0,22 \mathrm{~W} / \mathrm{mK}$. 
A adoção da espessura de $15 \mathrm{~mm}$ como parâmetro de comparação, nota-se uma diferença de aproximadamente $1,5^{\circ} \mathrm{C}$ entre os corpos de prova com e sem fibras quando a temperatura interna da caixa estava em aproximadamente $70^{\circ} \mathrm{C}$. Exatamente nas mesmas condições, a diferença entre os corpos de prova de $50 \mathrm{~mm}$ foi de $2,5^{\circ} \mathrm{C}$. Além disso, verificou-se que a diferença entre as curvas de $50 \mathrm{~mm}$ se inicia com cerca de 30 minutos de operação do ensaio enquanto a diferença entre as curvas de $15 \mathrm{~mm}$ começa apenas depois de 50 minutos de seu início. Tal situação é explicada pela maior isolação térmica que a fibra de coco proporciona em função da maior espessura do corpo de prova. Assim, constata-se que o tratamento desenvolvido para minimizar a degradação da fibra de coco não influenciou a sua capacidade de isolação térmica. Este resultado está de acordo com os trabalhos de AMARAL et al. [23], COSTA et al. [24] e OLIVEIRA et al. [25] que confirmam a viabilidade da fibra de coco como um material adequado para ser utilizado como isolante térmico.

Após o último desligamento da lâmpada incandescente, ocorreu uma brusca queda de temperatura no interior da caixa em função da ausência da fonte de calor registrada pela curva REFI. Isso provocou uma mudança de comportamento nas demais as curvas. Os corpos de prova sem a presença de fibras, mais aquecidos até então, perderam calor mais rapidamente em relação aos com fibras de coco, conforme pode ser visualizado entre o período de 75 a $150 \mathrm{~min}$. A partir de $150 \mathrm{~min}$ nota-se uma paridade entre as curvas, indicando que não há mais diferença de temperatura entre as mesmas. A pequena variação de temperatura constatada neste período está relacionada com os ciclos do termostato do condicionador de ar do laboratório.

O indicador coeficiente de atenuação térmico relativo (CAT) provocado pela incorporação da fibra no compósito pode ser visualizado na Figura 6 para suas espessuras de amostras. O CAT15 é dado pela relação entre a temperatura externa do corpo de prova S-F15 dividida pela temperatura externa do corpo de prova SL15, em função do tempo. Já o CAT50 estabelece a mesma relação para os corpos de prova de $50 \mathrm{~mm}$ de espessura.

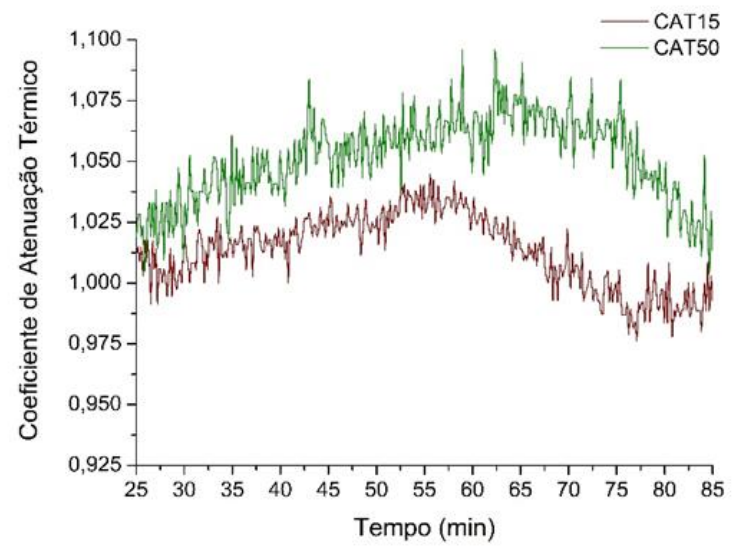

Figura 6: Gráfico de registros dos coeficientes de atenuação térmico relativo para as espessuras de 15 e $50 \mathrm{~mm}$ dos corpos de prova.

No intervalo de tempo em que a temperatura interna estava elevada ( 25 a $75 \mathrm{~min}$ ), constatou-se o efeito isolante dos corpos de prova com fibra em relação aos sem fibras, visto que o valor dos coeficientes foi maior que 1 no período. Além disso, nota-se também, que o coeficiente CAT50 indica que a maior espessura do corpo de prova com $50 \mathrm{~mm}$ proporciona maior poder de isolamento térmico. A partir do tempo $80 \mathrm{~min}$, com a temperatura interna da caixa mais baixa e estabilizada, não houve variações em relação aos coeficientes de atenuação térmicos.

A Figura 7A indica que de acordo com o aumento da espessura do corpo de prova, há uma tendência de crescimento da diferença de temperatura entre os corpos de prova com fibras (S-L) e sem fibras (S-F). Na condição de temperatura interna máxima (cerca de 70 minutos), constata-se uma menor temperatura externa dos corpos de prova de $50 \mathrm{~mm}$ em relação aos de $15 \mathrm{~mm}$, principalmente no corpo de prova com fibra de coco (curva S-L). Ao se fazer a extrapolação das curvas de temperatura em função da espessura do corpo de prova, pode-se esperar que a diferença de temperatura entre os corpos de prova de $100 \mathrm{~mm}$ com e sem fibra de coco seria de aproximadamente $5^{\circ} \mathrm{C}$, demonstrando o potencial das fibras de coco em relação à isolação térmica. 
a)

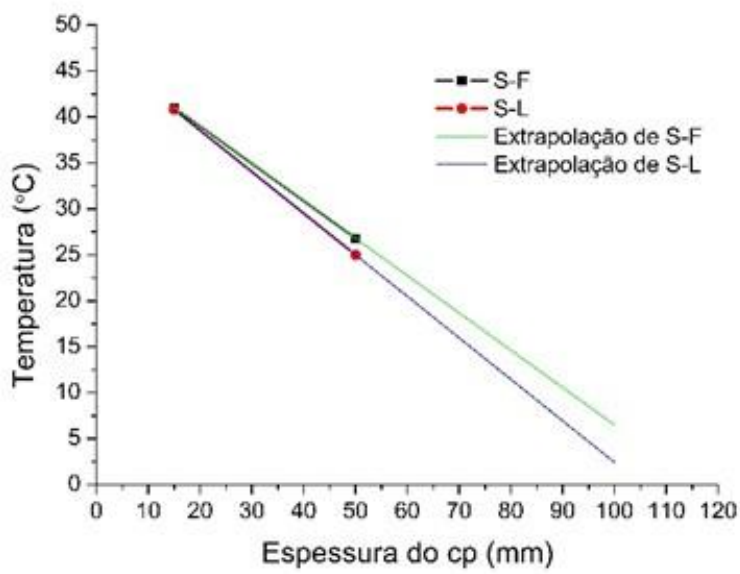

b)

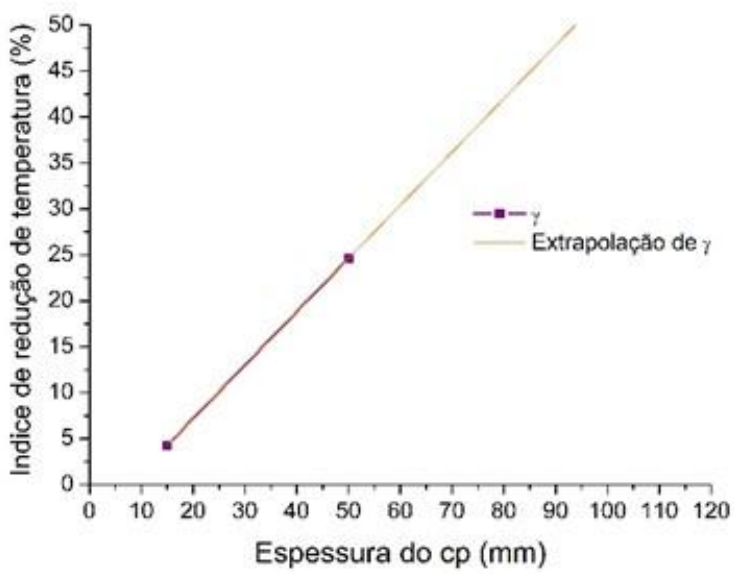

Figura 7: Gráfico da variação da temperatura das curvas S-F e S-L em dependência da espessura do corpo de prova (A); variação de $\gamma$ em função da espessura do corpo de prova (B).

O índice relativo de redução de temperatura $(\gamma)$, dado em \%, e calculado através da relação entre a diferença de temperatura entre os corpos de prova sem fibra e com fibra pela diferença de temperatura entre o corpo de prova sem fibra e a temperatura ambiente, apresentou expressiva variação em função da espessura. Observa-se na Figura 7B que enquanto a espessura do corpo de prova de 50mm registrou $\gamma$ de aproximadamente $25 \%$, espera-se através da extrapolação realizada, que o $\gamma$ possa atingir aproximadamente $50 \%$ com a espessura de $100 \mathrm{~mm}$, ou seja, um resultado promissor para a atenuação térmica. Outro indicador que também indicou essa tendência foi o gradiente de redução de temperatura por unidade de espessura ( $\beta$ ), calculado através da relação entre a diferença de temperatura das faces interna e externa dos corpos de prova pela sua espessura. Os resultados mostram que enquanto o $\beta_{\mathrm{SF}}$ apresentou $0,57^{\circ} \mathrm{C} / \mathrm{mm}$, o $\beta_{\mathrm{SL}}$ registrou $0,63^{\circ} \mathrm{C} / \mathrm{mm}$. Ou seja, o compósito com fibra de coco (S-L) melhorou a capacidade de isolação térmica em cerca de $10 \% \mathrm{em}$ relação ao compósito sem fibra de coco $(\mathrm{S}-\mathrm{F})$.

A partir do exposto, pode-se concluir através dos indicadores de atenuação térmica, índice relativo de redução de temperatura e gradiente de redução de temperatura que a fibra de coco tratada, nas condições propostas, confere uma maior capacidade de isolação térmica em relação ao compósito sem fibra de coco.

\subsection{Indicadores de desempenho acústico}

A Figura 8 apresenta o resultado do ensaio de desempenho acústico dos corpos de prova. A curva de referência (REF) indicou o nível de intensidade sonora realizada através dos dados indicados pelo decibelímetro, que estava posicionado diretamente na frente da fonte emissora de som, sem quaisquer anteparos, com a frequência variando de $20 \mathrm{kHz}$ até $20 \mathrm{~Hz}$. 


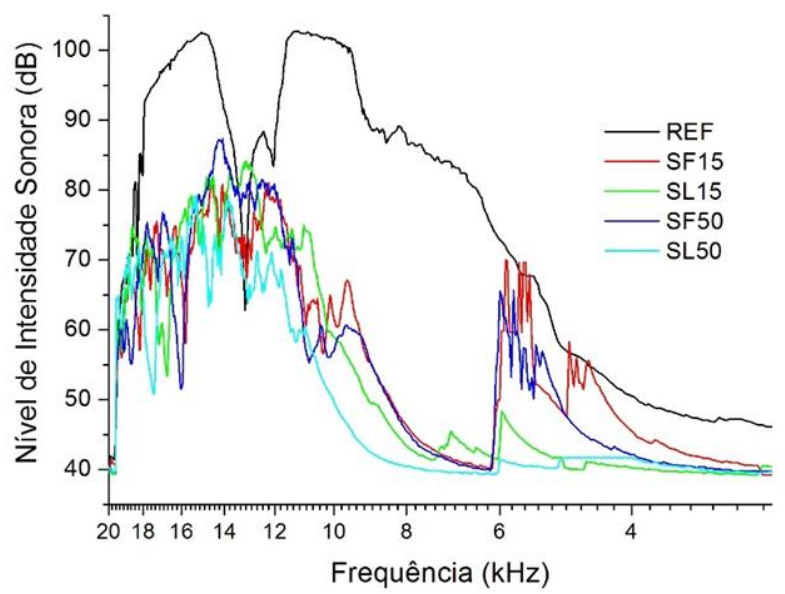

Figura 8: Gráfico dos resultados dos ensaios de desempenho acústico dos corpos de prova S-F 15, S-L 15, S-F 50 e S-L 50.

Em relação às curvas de desempenho da redução sonora promovida pelos compósitos, constatou-se uma grande variação comparada a curva de referência (REF). Os quatro corpos de prova testados foram capazes de diminuir a propagação de intensidade sonora, principalmente na região de baixa frequência da curva, onde a diferença chegou até cerca de $50 \mathrm{~dB}$ em relação à curva REF. Quando a análise é realizada entre os corpos de prova é possível verificar que o corpo de prova S-L 50, ou seja, com a presença de fibra de coco tratada e $50 \mathrm{~mm}$ de espessura, obteve melhor desempenho de redução sonora principalmente na região inferior a $10 \mathrm{kHz}$. Outra constatação verificada nesta região é a menor capacidade de evitar a transmissão de intensidade sonora do corpo de prova S-F 15, demonstrando que sua menor espessura $(15 \mathrm{~mm})$ associada à ausência de fibras de coco foi responsável por este comportamento.

Em relação às curvas observadas em frequências mais elevadas, observa-se uma diferença menor de desempenho entre os corpos de prova, entretanto, ainda é possível notar uma melhor capacidade de isolação sonora dos mesmos com a presença de fibra de coco. CUNHA [26] afirma que a incorporação da manta de fibra de coco em placas de gesso melhorou a absorção sonora. Segundo o autor, o efeito foi mais pronunciado em frequências mais baixas, por outro lado, em frequência mais elevadas, a presença das fibras não influenciou de maneira significativa a capacidade de absorção sonora.

Através da Figura 9, constata-se que o coeficiente de atenuação acústica relativo (CAC - calculado de maneira análoga ao CAT) nas frequências mais baixas, de fato, é maior que nas frequências mais elevadas. De forma similar ao ensaio térmico, o CAC50 também superou o CAC15, ou seja, a espessura de $50 \mathrm{~mm}$ do corpo de prova obteve maior atenuação acústica em relação à espessura de $15 \mathrm{~mm}$. Isso é explicado pela maior quantidade de fibra de coco no corpo de prova mais espesso que resulta em uma maior capacidade de atenuação sonora relativa.

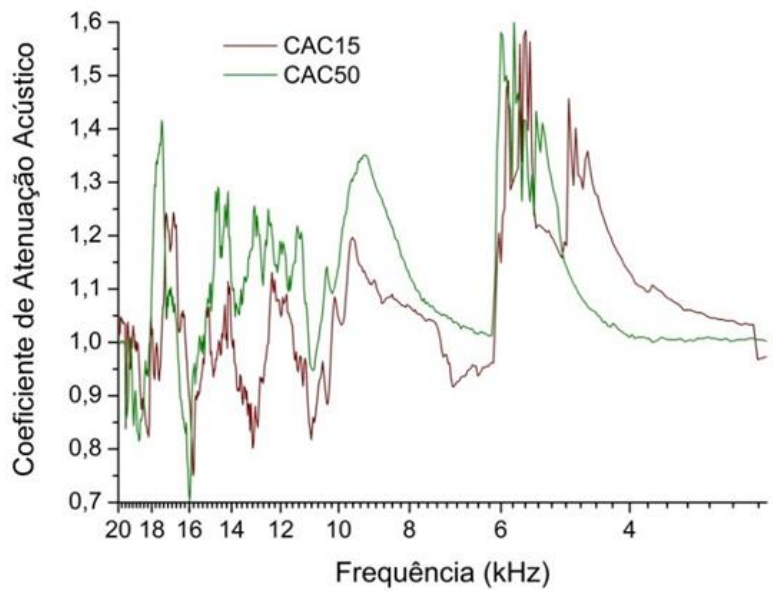

Figura 9: Gráfico de registro dos coeficientes de atenuação acústico relativo para as espessuras de 15 e 50 mm dos corpos de prova. 
Analisando especificamente o CAC50, percebe-se que seus valores chegam a atingir 1,35 e 1,6 para as frequências de aproximadamente 9 e $6 \mathrm{kHz}$, ou seja, 35 e $60 \%$ de melhoramento no isolamento acústico do compósito, o que confirma a viabilidade técnica do emprego de fibra de coco, nas condições propostas, para a capacidade de atenuação sonora do material. Em relação aos picos da curva CAC15 superiores à curva CAC50 registrados em baixas frequências, eles estão diretamente relacionados aos elevados picos do corpo de prova S-F 15 em relação aos baixos picos do corpo de prova S-L 15, visualizados na Figura 5. Mesmo com o CAC50 atingindo 1,4 (40\% de atenuação) à $17 \mathrm{kHz}$, deverão ser feitos novos trabalhos experimentais específicos na área de engenharia acústica para quantificar e qualificar mais precisamente o comportamento inferior a 1 dos CACs constatados em frequências mais elevadas.

\subsection{Propriedades mecânicas e durabilidade}

A durabilidade de uma substância afeta a sua resistência mecânica a diversos tipos de esforços. Se um material for menos durável em determinadas condições de existência, então, perderá em menor tempo suas características de resistência mecânica após o início do seu processo de degradação. Os ensaios de cura em ambiente aquoso foram complementados com os ensaios de resistência mecânica para que fossem avaliados os efeitos da adição de fibras de coco e outros agentes químicos à massa de cimento Portland.

A Figura 10 apresenta as curvas típicas envolvendo a aplicação de uma força versus a deflexão resultante e, também, a de resultados da tensão de tração na flexão dos compósitos desenvolvidos nas duas condições de cura avaliadas ( 28 dias e 28 dias e ciclagem).

a)

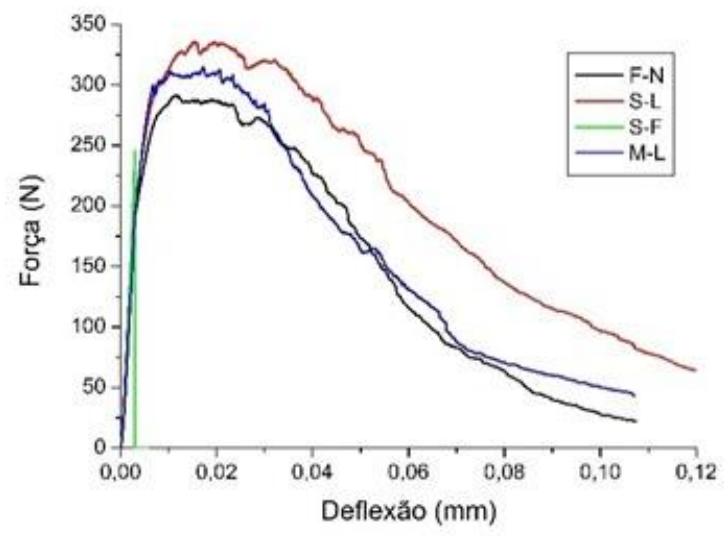

c)

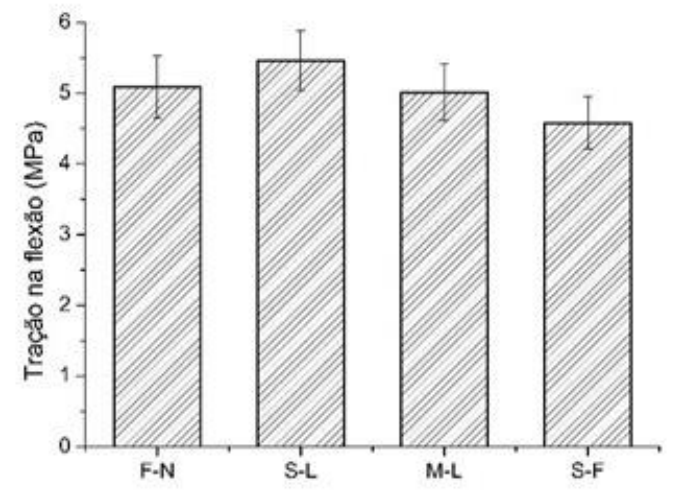

b)

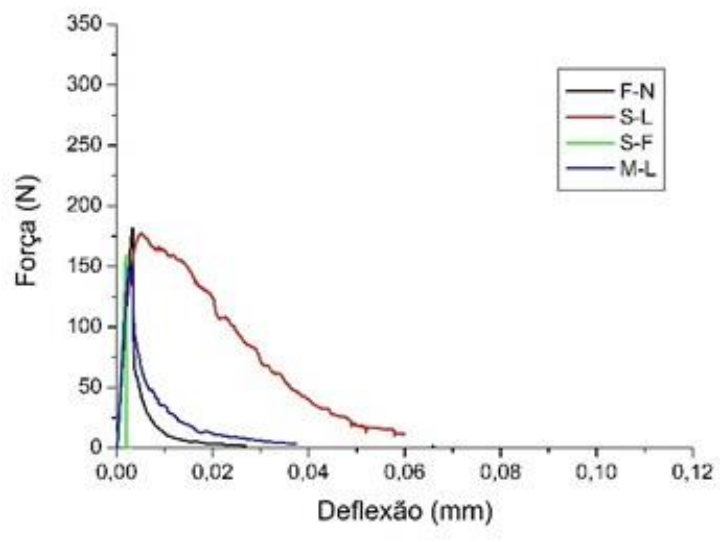

d)

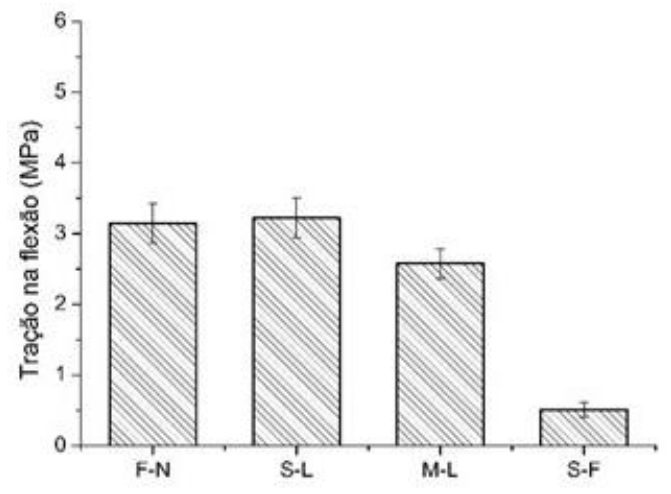

Figura 10: Curvas típicas de força aplicada x deflexão resultante dos compósitos na condição de cura após 28 dias de idade (A); após 28 dias de idade e ciclagem (B); tensão de tração na flexão dos corpos de prova rompidos após 28 dias de idade (C); tensão tração na flexão dos corpos de prova rompidos após 28 dias de idade e ciclagem (D). 
O compósito sem fibra de coco (S-F) apresentou comportamento frágil, com ocorrência de ruptura sem exibir capacidade de deformação, conforme verificado na Figura 10A. Nota-se também que a incorporação das fibras de coco nos compósitos (F-N, S-L e M-L) foi capaz de aumentar a força de necessária para a ruptura e, ainda mais importante, retardou o processo de rompimento do corpo de prova. Observa-se que enquanto o compósito M-L demonstrou comportamento pós-fissuração similar ao F-N, o compósito S-L obteve desempenho superior através da melhor capacidade de continuar suportando carga em deflexões mais elevadas devido às reações pozolânicas provocadas em função da presença de sílica ativa.

Em relação à Figura 10B, pode-se observar que o processo de envelhecimento acelerado provocou uma queda na força necessária para o rompimento. Este efeito foi mais pronunciado no compósito sem fibra de coco. A grande variação de umidade à elevada temperatura provocou uma redução da resistência do compósito S-F, provavelmente devido à grande fragilização das ligações químicas da matriz cimentícia. Seu comportamento frágil, sob tração e flexão, foi maximizado pelas condições de ciclagem, apresentando queda brusca de resistência após o surgimento da primeira fissura.

O envelhecimento acelerado também foi responsável pelo processo de degradação das fibras de coco dos compósitos F-N e M-L, pois se constatou grande diminuição da capacidade de manutenção de carga destes compósitos comparada à condição de cura sem envelhecimento. Por outro lado, o compósito S-L manteve um comportamento de deformação similar nas duas condições de cura. Isso indica que o tratamento efetuado através da combinação entre látex natural e sílica ativa foi capaz de manter o potencial das fibras de coco de evitar o colapso súbito do compósito. A redução da quantidade de $\mathrm{CH}$ no compósito é determinante para a manutenção da capacidade de deformação do compósito S-L após o processo de envelhecimento acelerado. Este fenômeno atrasa ou impede a degradação da fibra por ataque alcalino ou mineralização através da migração de hidróxido de cálcio (TOLÊDO FILHO et al. [27]).

Segundo PEREIRA et al. [28] a sílica ativa reage com o hidróxido de cálcio no interior do compósito, obtendo-se hidratos de silicato de cálcio na forma de gel $\left((\mathrm{CaO}) \mathrm{x} .\left(\mathrm{SiO}_{2}\right) \mathrm{y} .\left(\mathrm{H}_{2} \mathrm{O}\right) \mathrm{n}\right.$, de acordo com a seguinte reação:

$$
\mathrm{SiO}_{2} \mathrm{y}+\mathrm{xCa}(\mathrm{OH})_{2}+(\mathrm{N}-\mathrm{X}) \mathrm{H}_{2} \mathrm{O} \longrightarrow\left((\mathrm{CaO}) \mathrm{x}\left(\mathrm{SiO}_{2}\right) \mathrm{y}\left(\mathrm{H}_{2} \mathrm{O}\right) \mathrm{n}\right.
$$

Os resultados obtidos no presente trabalho indicam que a maior quantidade de pozolana aderida na superfície da fibra de coco (em função do filme adesivo de látex) pode ter proporcionado um efeito pozolânico local na interface fibra-cimento. $\mathrm{O}$ gel formado pela reação 8 diminui o pH local, aumenta a resistência e atribui coesão na ligação fibra-cimento (GUTIÉRREZ et al. [29]; WILD et al. [30]). Além do efeito pozolânico, é possível que a redução do espaço disponível provocado pelo filme polimérico tenha diminuído o transporte de íons na água, o que por sua vez reduz a quantidade de $\mathrm{CH}$ gerada no processo de hidratação (AFRID et al. [11] e BIJEN [12]). Estes fenômenos, de maneira interligada, explicam o aumento de resistência à tração na flexão e durabilidade dos compósitos estudados no presente estudo.

As Figuras 10C e 10D apresentam os valores de tensão de tração na flexão dos compósitos. Observase que mesmo substituindo $10 \%$ da massa do cimento por fibra de coco, o compósito F-N registrou um ganho de aproximadamente $11 \%$ de resistência em relação ao compósito sem fibras S-F. Esse resultado pode ser explicado pelo reforço da matriz cimentícia causado em virtude das ligações das fibras de coco com a matriz durante o processo de moldagem por adensamento e compactação do compósito.

O efeito do reforço físico causado pelas fibras de coco associado a presença da pozolana sílica ativa e látex natural (S-L) fez o aumento de desempenho subir para 19,2\% em relação ao compósito S-F. De acordo com a metodologia de análise múltipla de valores médios de Duncan, o compósito S-L é significativamente superior ao S-F nas duas condições de cura, indicando que a associação entre sílica ativa e látex natural melhorou o desempenho e durabilidade do compósito cimentício.

Embora a diferença dos valores de tensão de tração na flexão seja relativamente pequena após o processo de envelhecimento acelerado entre os compósitos F-N, M-L e S-L, pode-se afirmar que a melhor capacidade de deformação do compósito S-L, após a fissuração, demonstra a proteção que o tratamento realizado através da combinação entre látex natural e sílica ativa promoveu às fibras de coco. Além disso, enquanto na condição de envelhecimento acelerado o compósito S-F rompeu com apenas 0,51 MPa, o S-L obteve 3,22 $\mathrm{MPa}$, aproximadamente 6 vezes superior. Isso evidencia, de acordo com os parâmetros utilizados, a viabilidade técnica do tratamento protetor desenvolvido considerando que o compósito S-L utilizou 21,25\% menos cimento que o S-F.

O conjunto de imagens da Figura 11 apresenta o comportamento dos corpos de prova em várias etapas do procedimento de realização do ensaio de tração na flexão. A Figura 11A retrata as amostras do tipo F-N 
com e sem processo de ciclagem, ambas em estado de repouso sem submissão a um esforço de flexão. A Figura 11B expõe o rompimento do corpo de prova F-N sem a submissão a um processo de ciclagem. A Figura $11 \mathrm{C}$ apresenta o rompimento da amostra S-L com flexão e sem a submissão a um processo de ciclagem. A Figura 11D revela o rompimento do corpo de prova S-F submetida a um esforço de flexão, mas sem condicionamento na ciclagem. A Figura 11E apresenta o início do processo de rompimento da amostra F-N após sua ciclagem. A Figura 11F retrata um momento do processo de rompimento do S-L após ser submetido a um processo de ciclagem.

a)

b)

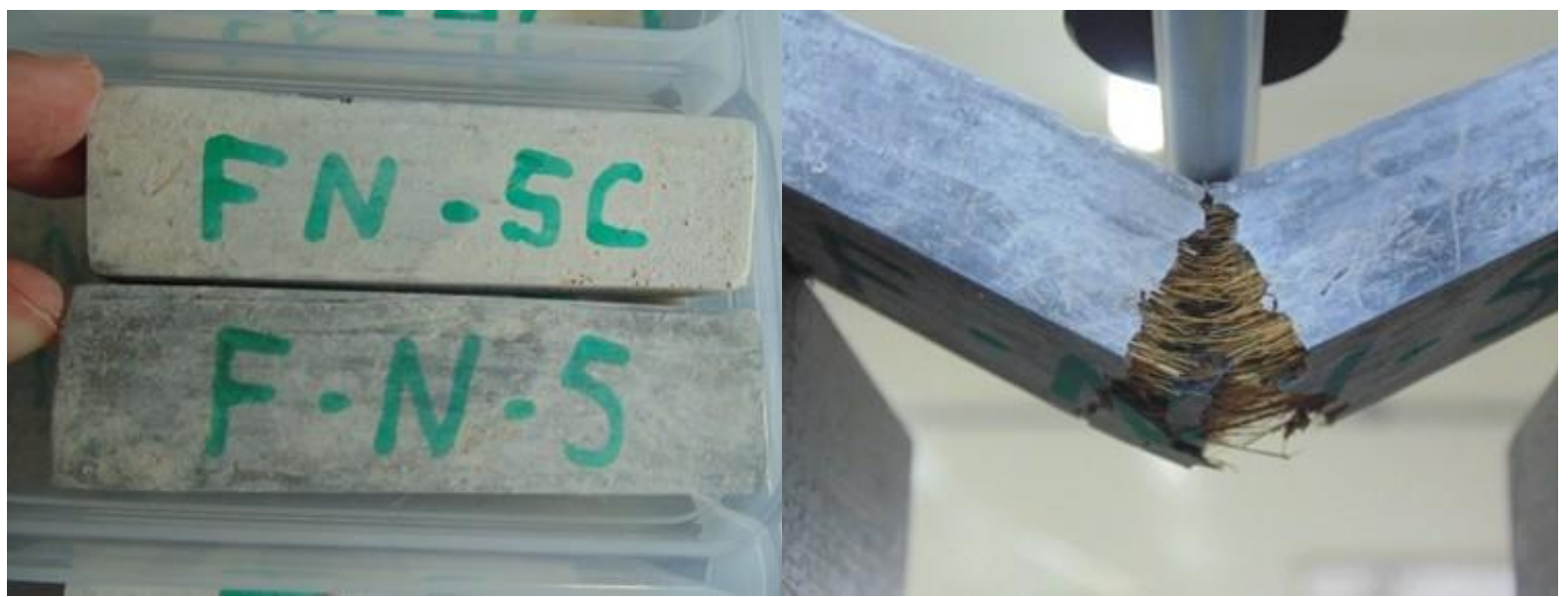

c)

d)

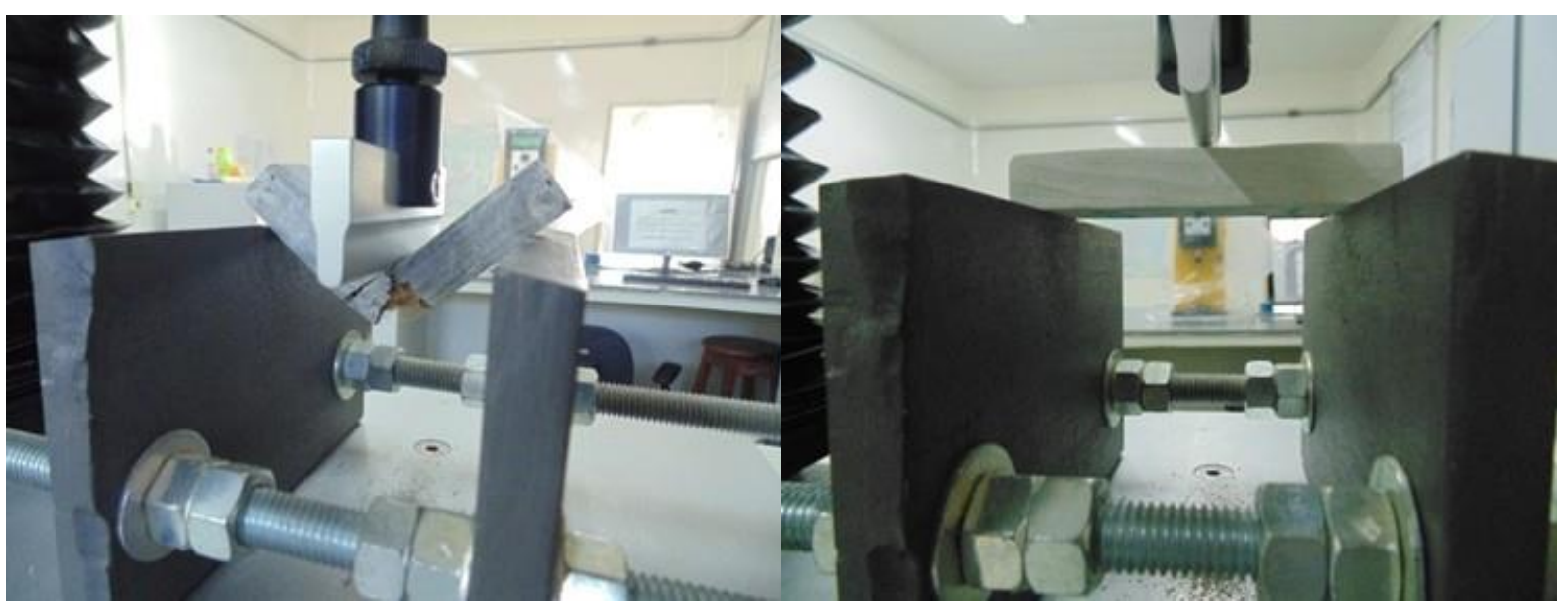

e)

f)

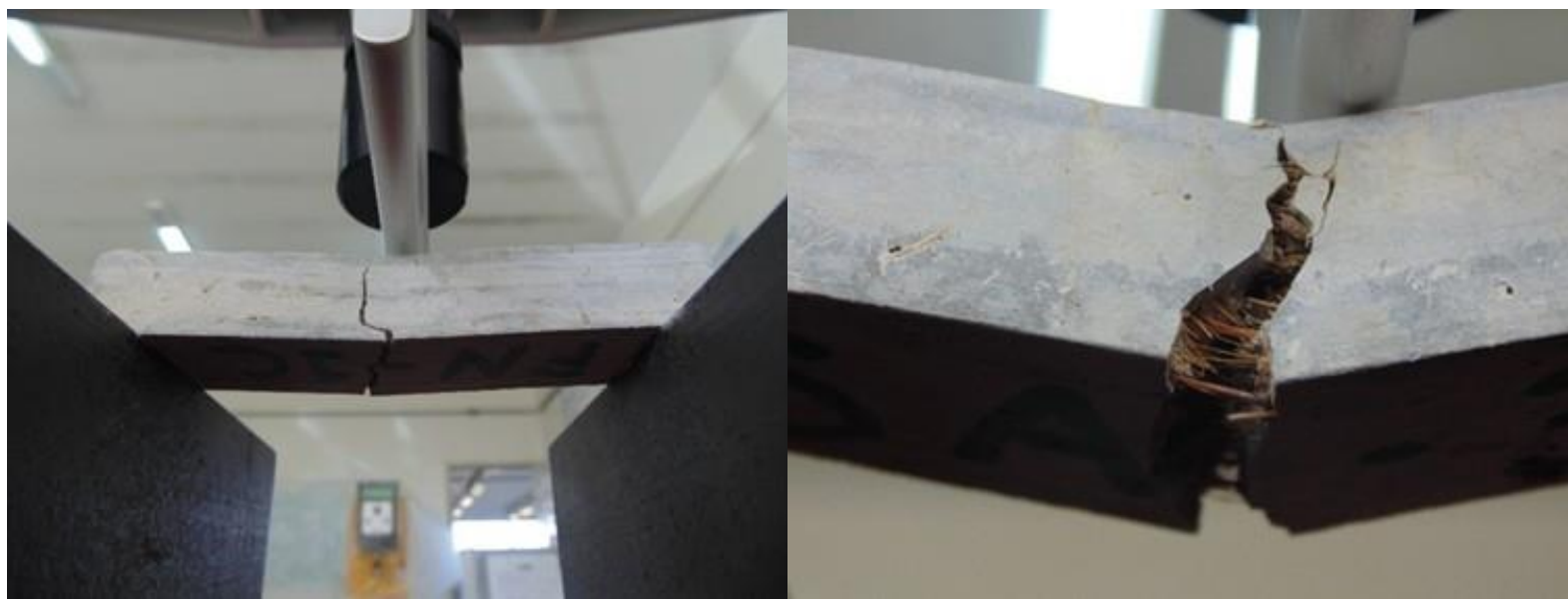

Figura 11: Imagens dos corpos de prova F-N com e sem processo de ciclagem (A); do rompimento do corpo de prova F$\mathrm{N}$ sem ciclagem (B); da fissuração do corpo de prova S-L sem ciclagem (C); do rompimento do corpo de prova S-F sem 
ciclagem (D); do início de rompimento do corpo de prova F-N com ciclagem (E); da fratura corpo de prova S-L com ciclagem e esforço de flexão $(\mathrm{F})$.

Através da Figura 11A, pode-se verificar a diferença entre o procedimento de cura dos compósitos com e sem o processo de ciclagem. Os corpos de prova que passam por este processo de envelhecimento acelerado apresentam uma maior quantidade de $\mathrm{CH}$ na superfície e, além disso, as fibras de coco aparecem mais destacadas e com coloração modificada em relação aos corpos de prova com apenas cura de 28 dias. Possivelmente os ciclos de secagem e molhagem carreiam $\mathrm{CH}$ para a face externa do corpo de prova aumentando a degradação da fibra de coco e contribuindo para a perda de sua capacidade de deformação.

As Figuras 11B e 11C mostram a capacidade das fibras de coco em evitar o colapso imediato dos corpos de prova, após o tratamento resultante pela da combinação entre látex natural e sílica ativa, que evitou a divisão do corpo de prova em duas partes mesmo com um esforço de deformação elevado. Um efeito contrário pode ser observado na Figura 11D, que apresenta o instante imediatamente anterior a ruptura do corpo de prova S-F, ou seja, praticamente sem deformação em função da fragilidade da matriz cimentícia. Esse fenômeno também foi relatado por PEREIRA et al. [28], MELO FILHO et al. [31] e LIMA et al. [32]. PALHETA et al. [33] afirmam que a adição de fibras da casca do coco em argamassa de cimento Portland para a confecção de painéis pré-moldados resulta em um compósito com maior resistência ao impacto e maior capacidade de absorção de energia. Essas características permitem o uso dos painéis nos mais diversos tipos de construção.

O efeito do envelhecimento acelerado nos corpos de prova é apresentado nas Figuras 11E e 11F. Há uma queda na capacidade de deformação dos compósitos F-N e S-L. Observou-se experimentalmente que o corpo de prova S-L continuou suportando o esforço mecânico mesmo apresentando grandes deformações, e este efeito indicou que o tratamento foi capaz de diminuir consideravelmente o processo de degradação das fibras de coco. Esse resultado revela que existe viabilidade técnica para a combinação entre látex natural e sílica ativa no sentido de conferir maior durabilidade aos compósitos cimentícios produzidos com fibra de coco.

O bom desempenho obtido por essa formulação foi validado para aplicação específica na construção civil ao se fazer uma comparação com os requisitos adotados por normas brasileiras. A norma ABNT 7170 [15] define resistência à compressão mínima de $4 \mathrm{MPa}$ para classificar tijolos cerâmicos na categoria $\mathrm{C}$, que é a de melhor qualidade para a construção civil. A norma ABNT NBR 6136 [34] aplicável a bloco de concreto para alvenaria estrutural define resistência mínima de 8 MPa, enquanto a norma ABNT NBR 15270-2 [35], que trata de blocos cerâmicos, exige $3 \mathrm{MPa}$ de resistência à compressão. A partir do exposto, pode-se considerar que o valor de 11,78 +/- 0,39 MPa obtido pelo tijolo produzido com o compósito S-L no teste de resistência à compressão, indica que o mesmo poderia ser utilizado como tijolo maciço para construção de edificações no Brasil. Por outro lado, GRAUPNER e MUSSIG [36] concluíram que materiais que utilizam fibras naturais ainda não podem ser usados em áreas que exigem padrões elevados de segurança contra incêndio, dessa forma esses tijolos são recomendados para ambientes com reduzidas probabilidades de ocorrência de fogo ou incêndio.

A Figura 12 apresenta a comparação visual entre o tijolo maciço produzido com o compósito S-L e um tijolo maciço cerâmico convencional adquirido numa loja de material de construção em Ilhéus-BA. É possível observar uma melhor qualidade de acabamento do tijolo S-L, principalmente nas extremidades, vértices e arestas sem falhas, além de ser mais resistente e leve que o tijolo cerâmico. 


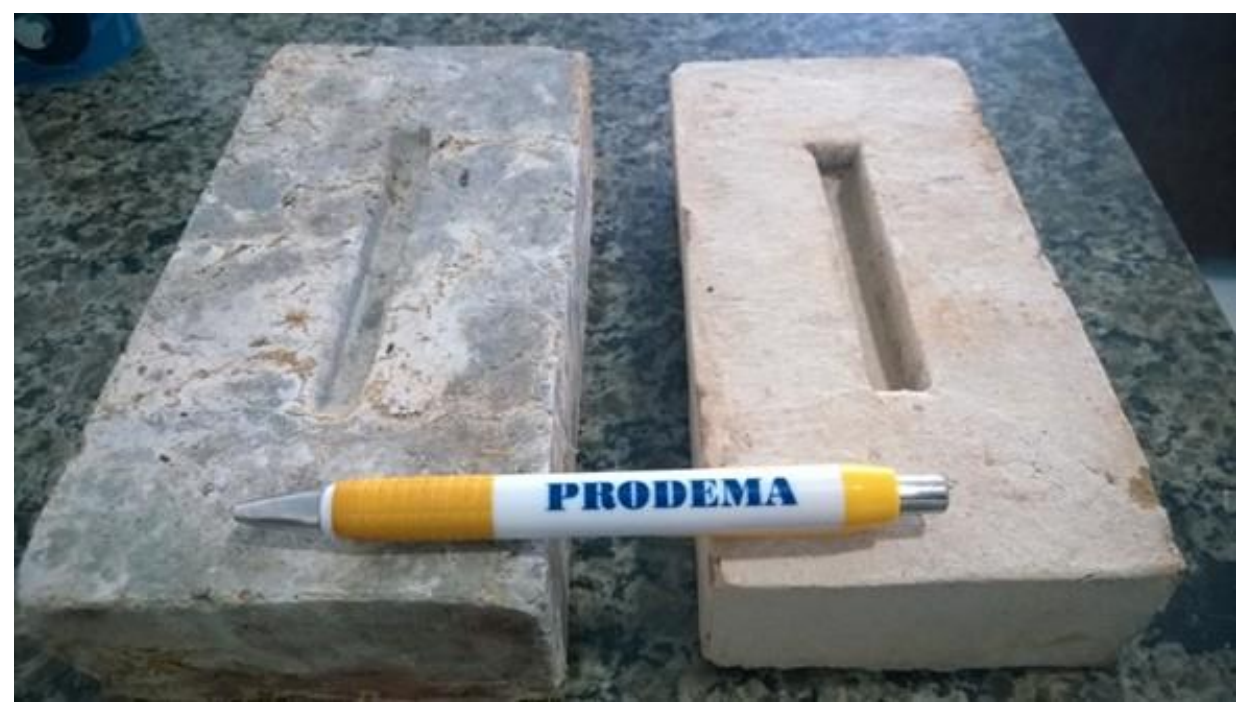

Figura 12: Tijolo maciço produzido com o compósito S-L (à esquerda) ao lado de um tijolo maciço cerâmico (à direita) adquirido em Ilhéus-BA.

\section{CONCLUSÕES}

De acordo os resultados experimentais e com as análises de massa específica, indicadores de atenuação térmica/acústico, índice relativo de redução de temperatura e gradiente de redução de temperatura, constatou-se que a incorporação da fibra de coco em matrizes cimentícias, tratadas com o teor proposto de $10 \% \mathrm{p} / \mathrm{p}$ diminui a massa específica e melhora o desempenho termoacústico do novo compósito em até $20 \% \%$ por comparação com o desempenho do compósito cimentício sem a sua presença.

O compósito produzido com $10 \%$ p/p de fibra de coco em relação à massa do cimento Portland, que foi tratada pela combinação entre látex natural e sílica ativa, apresentou um desempenho satisfatório quando submetido a condição de envelhecimento acelerado e ensaios de resistência à tração na flexão do compósito antes e depois dos processos de cura e tratamento. O compósito desenvolvido atende às exigências normativas brasileiras mínimas para ser utilizado como tijolo maciço, sem necessidade do emprego de aditivos plastificantes redutores de água.

As propriedades do novo compósito (massa específica reduzida e atenuação térmica/sonora) associadas à elevada resistência à tração na flexão e resistência à compressão sugerem que este material pode ser aproveitado na construção civil para produção de tijolos de alvenaria para vedação, desde que aplicado em ambientes com reduzidas probabilidades de ocorrência de fogo ou incêndio.

\section{AGRADECIMENTOS}

Os autores gostariam de agradecer as instituições públicas: Instituto Federal de Educação, Ciência e Tecnologia da Bahia - Campus Eunápolis (IFBA), Fundação de Amparo à Pesquisa do Estado da Bahia (FAPESB), Universidade Estadual de Santa Cruz (UESC) e Universidade Estadual do Sudoeste da Bahia (UESB); e as empresas: Coquefibras Ltda, Metacaulim Ltda, Mucambo S.A. e Tecnosil Ltda.

\section{BIBLIOGRAFIA}

[1] DNPM - Departamento Nacional de Produção Mineral. Sumário Mineral 2014. Brasil. DNPM, Ministério de Minas e Energia, Governo Federal. 2015. Disponível em: www.dnpm.gov.br. Acessado em 06/11/2016.

[2] SNIC - SINDICATO NACIONAL DA INDÚSTRIA DO CIMENTO. Relatório anual 2013. Rio de Janeiro, SNIC, 2014. Disponível em www.snic.org.br. Acessado em 28/09/2016.

[3] METHA, P.K., MONTEIRO, P. J. M. Concreto: microestrutura, propriedades e materiais. $3^{\mathrm{a}}$ ed. São Paulo, IBRACON, 2008.

[4] IBGE - Instituto Brasileiro de Geografia e Estatística. Levantamento sistemático da produção agrícola. Rio de Janeiro, IBGE, v.29, pp. 1-113, 2016.

[5] AGOPYAN, V., SAVASTANO JUNIOR, H. Cinzas e aglomerantes alternativos. In: Freire, W. J; Beraldo, A. L. (Coordenadores) Tecnologias e materiais alternativos de construção., Campinas, Unicamp, 2003. 
[6] PEREIRA, C. L., SAVASTANO JUNIOR. H, PAYÁ, J., et al., Use of highly reactive rice husk ash in the production of cement matrix reinforced with green coconut fiber. Industrial Crops and Products. v.49, pp. 88-96. 2013.

[7] TOLÊDO FILHO, R. D., SCRIVENER, K., ENGLAND, G. L., et al., Durability of alkali-sensitive sisal and coconuts fibres in cement mortar composites. Cement \& Concrete Composites, n.22, pp.127-143, 2000.

[8] ARSÈNE, M. A., BILBA, K., SAVASTANO JUNIOR, H., et al., "Treatments of Non-wood Plant Fibres Used as Reinforcement in Composite Materials”, Materials Research, v.16, n.4, pp. 903-923, 2013.

[9] SANTOS, S. F., TONOLI, G. H. D., MEJIA, J. E. B., et al., "Non-conventional cement-based composites reinforced with vegetable fibers: A review of strategies to improve durability", Materiales de Construcción, v.65, e041, 2015.

[10] PEREIRA, C. L. Aproveitamento do resíduo do coco verde para produção de compósitos destinados à construção rural, Tese de D.Sc., - Faculdade de Zootecnia e Engenharia de Alimentos, Universidade de São Paulo, Pirassununga, 2012.

[11] AFRID, M. U. K., OHAMAT, Y., ZAFAR IQBAL, M., et al., Behaviour of $\mathrm{Ca}(\mathrm{OH})_{2}$ in polymer modified mortars, The International Journal of Cement Composites and Lightweight Concrete, v. 11, p. 235-244, 1989.

[12] BIJEN, J. "Improved Mechanical Properties of Glass Fibre Reinforced Cement by Polymer Modification”, Cement \& Concrete Composites, v. 12, pp. 95-101, 1990.

[13] SILVA, E. J., MARQUES, M. L., FORNARI JUNIOR, C. C. M., et al., “A new treatment for coconut fibers to improve the properties of cement-based composites - combined effect of natural latex/pozzolanic materials", Sustainable Materials and Technologies, v.12, pp. 44-51, 2017.

[14] ASSOCIAÇÃO BRASILEIRA DE NORMAS TÉCNICAS. NBR 15575: Edificações habitacionais Desempenho. Rio de Janeiro, 2013.

[15] WEI, J., MEYER, C. "Degradation rate of natural fiber in cement composites exposed to various accelerated aging environment conditions", Corrosion Science, v. 88, pp. 118-132, 2014.

[16] ASSOCIAÇÃO BRASILEIRA DE NORMAS TÉCNICAS. NBR 7170: Tijolo maciço cerâmico para alvenaria. Rio de Janeiro, ABNT, 1983.

[17] ASSOCIAÇÃO BRASILEIRA DE NORMAS TÉCNICAS. NBR 6460: Tijolo maciço cerâmico para alvenaria - verificação da resistência à compressão. Rio de Janeiro, ABNT, 1983.

[18] GUNASEKARAN, K., KUMAR, P. S., LAKSHMIPATH, M. "Mechanical and bond properties of coconut shell concrete", Construction and Building Materials, v.25, pp. 92-98, 2011.

[19] GUNASEKARAN, K., ANNADURAI, R.; KUMAR, P. S. A study on some durability properties of coconut shell aggregate concrete. Materials and Structures, v.48, pp. 1253-1264, 2015.

[20] ABDULLAH, A., JAMALUDIN, S. B., ANWAR, M. I., et al., "Assessment of Physical and Mechanical Properties of Cement Panel Influenced by Treated and Untreated Coconut Fiber Addition", Physics Procedia, v.22, pp. 263-269, 2011.

[21] RODRÍGUEZ, N. J., LIMÓN, M. Y., MICELI, F. A., et al., "Assessment of coconut fibre insulation characteristics and its use to modulate temperatures in concrete slabs with the aid of a finite element methodology", Energy and Buildings, v.43, pp. 1264-1272, 2011.

[22] RAMIREZ, A. R., CASTILHO, F. C., DOMINGUEZ, V. J. M., et al., "Thermal conductivity of coconut fibre filled ferrocement sandwich panels", Construction and Building Materials, v.37, pp. 425-431, 2012.

[23] AMARAL, L. G. T., GOMES, J. S., MENDES, J. U. L., et al., "Fibra da casca do coco como isolamento térmico de superfície aquecida", In: Desempenho térmico de sistemas construtivos alternativos, Natal, Brasil, 2003.

[24] COSTA, J. F., OLIVEIRA, C. V. D., OLIVEIRA, M. M. F., et al., "Isolamento térmico de coberturas com fibra de coco", In: Desempenho térmico de sistemas construtivos alternativos, Natal, Brasil, 2003.

[25] OLIVEIRA, M. M. F., ARAÚJO, V. M. D., MENDES, J. U. L., et al., "Isolamento térmico de coberturas através de fibra vegetal", In: Encontro nacional de conforto no ambiente construído, Curitiba, Brasil, 2003.

[26] CUNHA, P. W. S. Estudo sobre as potencialidades de compósitos à base de gesso e fibras de coco seco para aplicação na construção civil. Tese de D.Sc., Universidade Federal do Rio Grande do Norte, Natal, 2012. 
[27] TOLÊDO FILHO, R. D., GHAVAMI, K., ENGLAND, G. L., et al., "Development of vegetable fibremortar composites of improved durability”, Cement \& Concrete Composites, v. 25, pp. 185-196, 2003.

[28] PEREIRA, C. L., SAVASTANO JUNIOR. H, PAYÁ, J., et al., "Use of highly reactive rice husk ash in the production of cement matrix reinforced with green coconut fiber", Industrial Crops and Products. v.49, pp. 88-96, 2013.

[29] GUTIÉRREZ, R. M., DÍAZ, L. N., DELVASTO, S. "Effect of pozzolans on the performance of fiberreinforced mortars", Cement and Concrete Composites, v. 27, n. 5, pp. 593-598, 2005.

[30] WILD, S., KHATIB, J. M., JONES, A. "Relative strength, pozzolanic activity and cement hydration in superplasticised metakaolin concrete", Cement and Concrete Research, v. 26, n. 10, p. 1537-1544, 1996.

[31] MELO FILHO, J. A., SILVA, F. A., TOLÊDO FILHO, R. D. "Degradation kinetics and aging mechanisms on sisal fiber cement composite systems”, Cement \& Concrete Composites, v.40, pp. 30-39, 2013.

[32] LIMA, P. R. L., TOLEDO FILHO, R. D., MELO FILHO, J. A. “Compressive Stress-strain Behaviour of Cement Mortar-composites Reinforced with Short Sisal Fibre”, Materials Research, v.17, n.1, pp. 38-46, 2014.

[33] PAlhetA, E. R. S., PORTElA, C. S. A., CARVAlHO, A. B. L., et al., "Avaliação experimental da adição de fibras naturais da casca do coco babaçu como reforço de matriz cimentícia”, In: Congresso brasileiro do concreto, Maceió, Brasil, 2012.

[34] ASSOCIAÇÃO BRASILEIRA DE NORMAS TÉCNICAS. NBR 6136: blocos vazados de concreto simples para alvenaria - requisitos. Rio de Janeiro, ABNT, 2016.

[35] ASSOCIAÇÃO BRASILEIRA DE NORMAS TÉCNICAS. NBR 15270-2: blocos cerâmicos para alvenaria estrutura - terminologia e requisitos. Rio de Janeiro, ABNT, 2005.

[36] GRAUPNER, N., MUSSIG, J. Technical Applications of Natural Fibres: An Overview. In: MUSSIG, J. Industrial Applications of Natural Fibres - Structure, Properties and Technical Applications. Bremen, Germany, Wiley Series in Renewable Resources, 2010. 